\title{
Guideline for veterinary practitioners on canine ehrlichiosis and anaplasmosis in Europe
}

\author{
Ángel Sainz ${ }^{1 *}$, Xavier Roura ${ }^{2}$, Guadalupe Miró ${ }^{3}$, Agustín Estrada-Peña ${ }^{4}$, Barbara Kohn ${ }^{5}$, Shimon Harrus ${ }^{6}$ \\ and Laia Solano-Gallego ${ }^{7}$
}

\begin{abstract}
Canine ehrlichiosis and anaplasmosis are important tick-borne diseases with a worldwide distribution. Information has been continuously collected on these infections in Europe, and publications have increased in recent years. Prevalence rates are high for Ehrlichia and Anaplasma spp. infections in dogs from different European countries. The goal of this article was to provide a practical guideline for veterinary practitioners on the diagnosis, treatment, and prevention of ehrlichiosis and anaplasmosis in dogs from Europe. This guideline is intended to answer the most common questions on these diseases from a practical point of view.
\end{abstract}

Keywords: Canine ehrlichiosis, canine anaplasmosis, Ehrlichia canis, Anaplasma phagocytophilum, Anaplasma platys, consensus

\section{Introduction}

Canine ehrlichiosis and anaplasmosis are important tick-borne diseases with a worldwide distribution.

Ehrlichia canis was first identified in 1935 in Algeria; dogs infested with ticks showed fever and anemia [1]. Later, during the Vietnam War, many military working dogs brought to Vietnam by the US army exhibited a severe disease called Tropical Canine Pancytopenia [2]. Later, it was renamed canine monocytic ehrlichiosis (CME).

In 1978, an ehrlichial infection that affected platelets was first identified in the US. It was caused by Anaplasma platys (initially identified as Ehrlichia platys), and it caused a clinical syndrome known as canine infectious cyclic thrombocytopenia [3]. In 1982, a natural infection of granulocytic anaplasmosis, caused by Ehrlichia phagocytophila, was first identified in dogs in California. Currently, this species is called Anaplasma phagocytophilum [4].

Over the 1980's and 90's, several species closely related to E. canis were found in infected dogs. Improvements in molecular techniques indicated that they were

\footnotetext{
* Correspondence: angelehr@vet.ucm.es

'Department of Animal Medicine and Surgery, Veterinary Clinic Hospital, Faculty of Veterinary Medicine, Universidad Complutense de Madrid, Madrid, Spain

Full list of author information is available at the end of the article
}

phylogenetically distant from E. canis, and therefore, they were reclassified under the genera Anaplasma or Neorickettsia [5].

In 2002, a large amount of information on ehrlichial infections was gathered by the American College of Veterinary Internal Medicine (ACVIM) Infectious Disease Study Group. That group published a Consensus Statement on diseases caused by Ehrlichia spp. in small animals [6]. Over the years, and probably as a result of globalization, urbanization, global warming, increased trade, and travel, these diseases have spread to new niches. Recently, diseases caused by Ehrlichia spp have been reported in many countries that had not previously detected them. Information has been continuously collected on these infections, and publications have increased in recent years. This document was intended to answer common questions of interest on this group of infections, with a special focus on the situation in Europe.

\section{Review \\ What species of Ehrlichia and/or Anaplasma can infect dogs in Europe? \\ To date, three species have been clearly identified in dogs in Europe; E. canis, A. phagocytophilum, and A. platys.}




\section{Ehrlichia canis}

Ehrlichia canis is the only Ehrlichia species that has been isolated in dogs from Europe $[7,8]$. To our knowledge, other Ehrlichia species (E. chaffeensis, E. ewingii, $E$. muris, and E. ruminantium) have not been detected in dogs from Europe. However, E. muris has been described in Ixodes ticks from Russia and Slovakia $[9,10]$. All European countries bordering the Mediterranean Sea are endemic for E. canis. Some surveys have indicated that the infectious agent is spreading to countries north of the Mediterranean (i.e., Switzerland, Germany) [11-13]. Table 1 shows the prevalence of $E$. canis infections in dogs from Europe.

\section{Anaplasma phagocytophilum}

Infections of $A$. phagocytophilum have been described mainly in northern and central Europe. Epidemiological studies performed in Europe (Table 2) that evaluated the seroprevalence (rarely a DNA-based analysis) showed that 3 to $57 \%$ of dogs carried A. phagocytophilum. However, the different studies investigated different dog populations (i.e., healthy and sick), and they used different tests (i.e., immunofluorescent antibody test [IFAT] or enzymelinked immunosorbent assay [ELISA]). In addition, serological cross-reactivity with other Anaplasma spp. (e.g., A. platys) can potentially cause an overestimation of the true seroprevalence.

Table 1 Prevalence of $E$. canis infections in dogs of different European countries

\begin{tabular}{|c|c|c|c|c|}
\hline Country & Number of dogs (n) & Prevalence (\%) & Test methods & Reference \\
\hline Albania & 30 & $50.0 / 17.0$ & IFAT/Blood smear & {$[14]$} \\
\hline Finland & 340 & 0.3 & 4DX ELISA & [15] \\
\hline France & 919 & 0.3 & 4DX ELISA & [16] \\
\hline \multirow[t]{3}{*}{ Germany } & $106^{\mathrm{a}}$ & 0.9 & IFAT & {$[17]$} \\
\hline & $997^{a}$ & $3.1 / 0$ & IFAT/PCR & [18] \\
\hline & $4681^{a}$ & 10.1 & IFAT & [19] \\
\hline Hungary & 1305 & 0.2 & 4DX ELISA & [20] \\
\hline \multirow[t]{7}{*}{ Italy } & $249^{\mathrm{b}}$ & 46.0 & IFAT & [21] \\
\hline & 135 & $44.0 / 6.0$ & IFAT/PCR & [22] \\
\hline & 51 & 0 & PCR & [23] \\
\hline & $131^{\mathrm{b}}$ & 22.9 & IFAT & [24] \\
\hline & 601 & 6.4 & $P C R$ & {$[25]$} \\
\hline & 1000 & 46.7 & IFAT & {$[26]$} \\
\hline & 423 & 20.0 & IFAT & {$[27]$} \\
\hline \multirow[t]{3}{*}{ Portugal } & 557 & 4.1 & 4Dx ELISA & {$[28]$} \\
\hline & 55 & 22.0 & $P C R$ & [29] \\
\hline & 104 & 50.0 & IFAT & {$[30]$} \\
\hline Romania & 1146 & 2.1 & 4DX ELISA & [31] \\
\hline Russia & $442^{c} 82^{d}$ & 02.4 & 4DX ELISA & [32] \\
\hline \multirow[t]{7}{*}{ Spain } & 1100 & 5.0 & 4DX ELISA & [33] \\
\hline & 131 & 5.3 & 4DX ELISA & [34] \\
\hline & 153 & $4.0^{e}$ & $P C R$ & [35] \\
\hline & 479 & 3.1 & IFAT & [36] \\
\hline & 466 & 16.74 .5 & IFAT 3DX ELISA & {$[37]$} \\
\hline & 200 & 6.5 & IFAT & {$[38]$} \\
\hline & 308 & 19.2 & IFAT & [39] \\
\hline Switzerland & $996^{a}$ & 2.2 & IFAT & [13] \\
\hline Turkey & 284 & 20.7 & IFAT & {$[40]$} \\
\hline
\end{tabular}

${ }^{\text {a Travelled/imported dogs. }}$

${ }^{\mathrm{b}}$ Kenelled dogs.

'Dogs with external antiparasitary treatment.

${ }^{\mathrm{d}}$ Dogs without external antiparasitary treatment.

eUsing primers for Ehrlichia/Anaplasma. 
Table 2 Prevalence of infections with A. phagocytophilum in dogs of different European countries

\begin{tabular}{|c|c|c|c|c|}
\hline Country & Number of dogs (n) & Prevalence (\%) & Test methods & Reference \\
\hline Austria & 1470 & 56.5 & IFAT & [41] \\
\hline Albania & 30 & $40.0 / 0$ & IFAT/Blood smear & [14] \\
\hline Finland & 340 & 5.3 & $4 D x$ ELISA ${ }^{a}$ & [15] \\
\hline France & 919 & 2.7 & 4Dx ELISA ${ }^{a}$ & [16] \\
\hline \multirow[t]{6}{*}{ Germany } & 1124 & 50.1 & IFAT & {$[42]$} \\
\hline & 111 & 43.2 / 6.3 & IFAT/PCR & [43] \\
\hline & 245 & 19.2 & IFAT & [44] \\
\hline & 5881 & 21.5 & 4Dx ELISA ${ }^{a}$ & [45] \\
\hline & 522 & $43.0 / 5.7$ & IFAT/PCR & {$[46]$} \\
\hline & 448 & 19.4 & 4Dx ELISA ${ }^{a}$ & {$[47]$} \\
\hline Hungary & 1305 & 7.9 & 4Dx ELISA ${ }^{a}$ & [20] \\
\hline \multirow[t]{6}{*}{ Italy } & 344 & 0 & $P C R$ & {$[48]$} \\
\hline & 460 & 0 & PCR & {$[25]$} \\
\hline & 5634 & 33.0 & IFAT & [49] \\
\hline & 1232 & 8.8 & IFAT & {$[50]$} \\
\hline & 249 & 38.0 & IFAT & [21] \\
\hline & 215 & $15.0 / 0.02$ & IFAT/PCR & {$[51]$} \\
\hline Latvia & 470 & 11.4 & 4Dx ELISA ${ }^{a}$ & {$[52]$} \\
\hline Poland & 192 & 1.0 & PCR & {$[53]$} \\
\hline Portugal & 55 & $55.0 / 0$ & IFAT/PCR & {$[54]$} \\
\hline Romania & 1146 & 5.5 & 4DX ELISA ${ }^{a}$ & [31] \\
\hline Russia & $442^{b} 82^{c}$ & 1.134 .1 & $4 D \times E^{2} I S A^{a}$ & [32] \\
\hline \multirow[t]{2}{*}{ Sweden } & 611 & 17.7 & IFAT & {$[55]$} \\
\hline & 248 & 20.7 & IFAT & {$[56]$} \\
\hline Switzerland & 996 & 7.5 & IFAT & [13] \\
\hline \multirow[t]{3}{*}{ Spain } & 649 & 15.6 & IFAT & [36] \\
\hline & 466 & 11.5 & IFAT & {$[37]$} \\
\hline & 1100 & 3.1 & 4Dx ELISA ${ }^{a}$ & [33] \\
\hline United Kingdom & 120 & 0.8 & $P C R$ & {$[57]$} \\
\hline
\end{tabular}

${ }^{a}$ This test cannot differentiate between A. phagocytophilum and A. platys.

${ }^{b}$ Dogs with external antiparasitary treatment.

${ }^{c}$ Dogs without external antiparasitary treatment.

\section{Anaplasma platys}

Anaplasma platys has been diagnosed in dogs, particularly from countries in the Mediterranean basin, including Italy [48], Spain [58], Portugal [59], France [60], Turkey [61], Greece [62], Croatia [63], and Romania [64]. Information is limited regarding the prevalence of A. platys infections in dogs from Europe, based on a molecular analysis (Table 3).

What are the vectors and geographic distributions of vectors for these infections in dogs in Europe?

\section{Ehrlichia canis}

The main, and probably the only, vector for E. canis in Europe is the tick Rhipicephalus sanguineus sensu lato, known as the brown dog-tick. This tick was shown
Table 3 Prevalence of infections with A. platys in dogs in Europe

\begin{tabular}{lllll}
\hline Country & $\begin{array}{l}\text { Number of } \\
\text { dogs }(\mathbf{n})\end{array}$ & Prevalence (\%) & $\begin{array}{l}\text { Test } \\
\text { methods }\end{array}$ & Reference \\
\hline Italy & $34^{\mathrm{a}}$ & 52.9 & PCR & {$[65]$} \\
& $34^{\mathrm{a}}$ & 70.5 & PCR & {$[66]$} \\
& $109^{\mathrm{a}}$ & 27.5 & PCR & {$[67]$} \\
& 344 & 4 & PCR & {$[48]$} \\
& $100^{\mathrm{a}}$ & 23 & RLB-PCR & {$[68]$} \\
Portugal & $55^{\mathrm{b}}$ & 9 & IFAT/PCR & {$[54]$} \\
\hline
\end{tabular}

${ }^{\mathrm{a}}$ Kenelled dogs.

${ }^{\mathrm{b}}$ Dogs with suspected tick-borne diseases. 
experimentally to be a competent vector for $E$. canis $[69,70]$. A recent study has shown that transmission of E. canis by $R$. sanguineus ticks starts within $3 \mathrm{~h}$ after tick attachment to the dog [71]. The tick vector is currently considered a complex of species [72]. The details of this vector's morphology and molecular biology have been published, and it has been identified in wide areas of the world. However, it is difficult to ascertain which "species" comprise the actual vector, because the description of the original specimen type has been lost [72].

Rhipicephalus sanguineus is abundant in the Mediterranean basin. When introduced to colder areas, due to movements of the host (i.e., dogs travelling to and returning from the Mediterranean region), it can survive in kennels and other protected areas provided by man-made constructions (Figure 1). The latitude at which the tick can be established is currently unknown [72,73]. Protected environments, such as a house, a kennel, or the den of a wild carnivore, provide an ideal environment for the reproduction and survival of tick populations. It has been reported that even a single tick female was sufficient to engorge and oviposit on a dog inside an apartment, which then could give rise to the development of subadults [74]. Rhipicephalus sanguineus populations can reach very high numbers in sheltered environments, because the blood supply necessary for their development is guaranteed by the presence of hosts in close proximity. In dogs without appropriate protection, parasitic loads can reach hundreds of ticks per animal, with ticks in all developmental stages.

The tick requires a minimum temperature of about $6^{\circ} \mathrm{C}$ for adequate survival, and when temperatures drop below this value, it may hibernate during winter, sheltered in the cracks of kennels and buildings. Ticks also require a certain level of humidity, which is provided by the high environmental moisture in the kennels (cleaned with water) or in gardens that receive artificial watering. Ticks are common and can reach significant population densities on riverbanks of the Mediterranean region, which are temperate and hold moisture. The tick is mainly active from spring to early autumn, when the highest infestations occur. The regional weather or the local conditions of some buildings may result in a different phenology or in different seasonal dynamics for the tick [72]. The impact of climate trends on the tick is unknown, although preliminary results have shown that

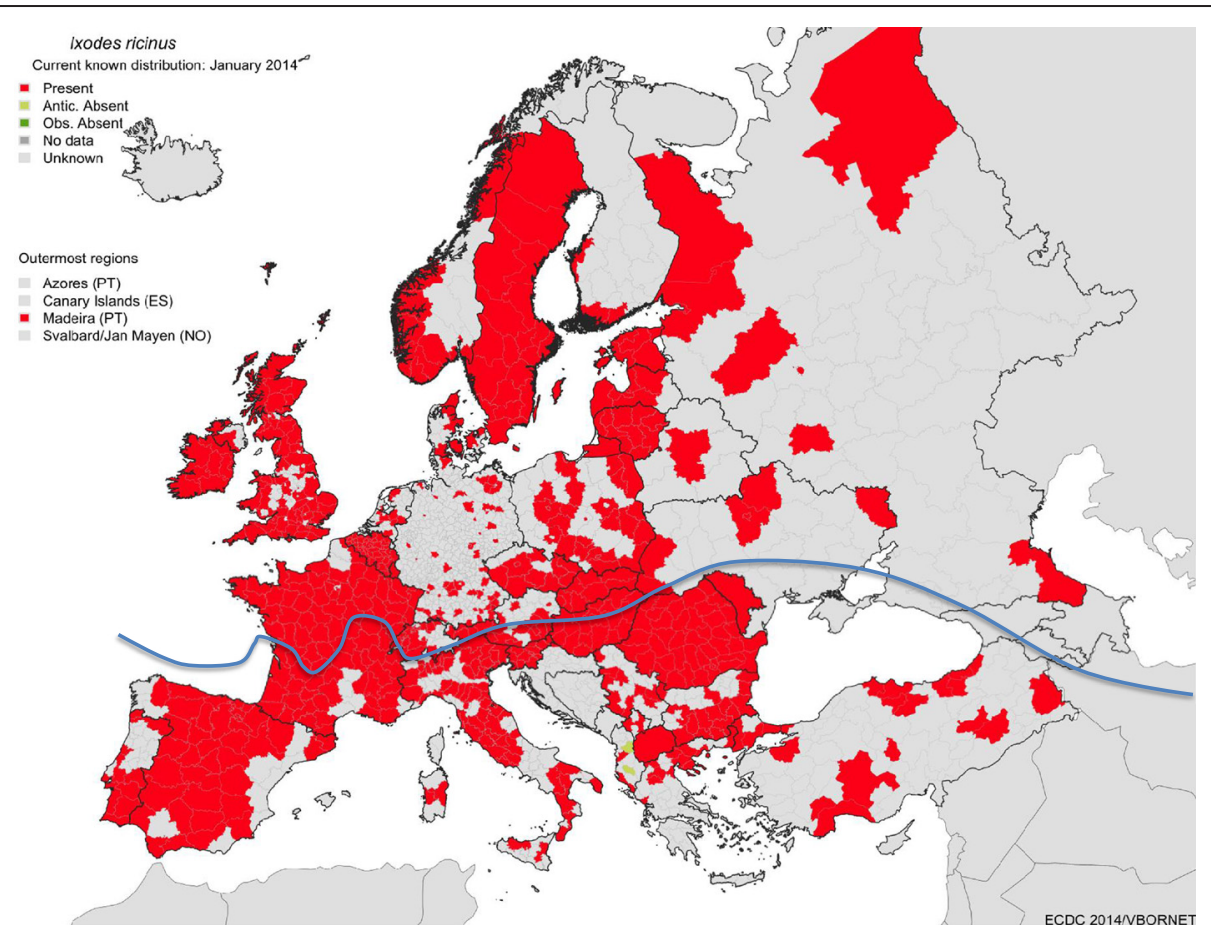

Figure 1 Distribution of Ixodes ricinus and Rhipicephalus sanguineus in Europe. The reported distribution of I. ricinus was officially recorded by the European Center for Disease Control (ECDC) in January, 2014 (red areas). The map includes only records with reliable, accurate data that can be ascribed to one of the NUTS (statistical regions of Europe). Many reports in the literature only mention the presence of one species in a country. Some of the areas in the Mediterranean region might be based on identified collections that do not have permanent populations (i.e., casual introduction without further survival) or based on small areas of suitability. The line shows the northern range of the distribution of ticks that belong to the $R$. sanguineus complex. Due to the confusion surrounding the morphology and systematics of this complex group, many records cannot be confidently tracked as "true" $R$. sanguineus. This northern limit is also an educated guess for the current distribution, because persistent populations may live in northern latitudes, protected in shelters, burrows, or private gardens, where adequate conditions for survival may exist. 
their area of distribution is increasing, due to the increase in urbanized areas surrounding cities, and due to the warmer environment observed in autumn and winter at progressively higher latitudes.

\section{Anaplasma phagocytophilum}

Ixodes ricinus is the only known vector for $A$. phagocytophilum in Europe. This tick is widely distributed in most European regions, including western Norway and in Sweden; it has been collected in mixed forests, open pastures, and other areas with high humidity (Figure 1). The driving feature of the northern distribution is the temperature required for tick development. In the northern areas of Sweden, the tick was found at an approximate latitude of $68^{\circ} \mathrm{N}$, but some tick populations have spread even farther north [75]. Ixodes ricinus is present in Ireland, the United Kingdom, and in southern Finland. It is also present in almost every territory in central Europe, and the eastern limit seems to be along the Baltic countries and Ukraine. At its present limit to the east, it coexists with the closely-related, species Ixodes persulcatus, with which there is a certain degree of sympatry. In the south, the tick is present in parts of the Mediterranean region, commonly in mixed or deciduous forests [76,77]. It has been detected in Portugal, Spain (only in northern areas of the country and isolated points in southern hills), and Italy. It is also common in the northern belt of humid forests in Turkey [76,77]. It is hypothesized that the driving feature of its southern distribution is the atmospheric water vapour, which must be relatively high (around 80\%) to support permanent populations.

In the eastern regions of Europe, I. ricinus is replaced with $I$. persulcatus, a closely related species. The habitats of $I$. persulcatus extend to the east and into Japan [78]. This well-known parasite inhabits a wide range of domestic animals, and it acts as a vector for different pathogens. It is probably best known as the main vector for Borrelia spp. and for tick-borne encephalitis virus in the territories it colonizes [79]. I. persulcatus was found to be infected by Ehrlichia spp. in the Baltic region [80] and by A. phagocytophilum in Ukraine [81]. Members of the Anaplasmataceae family (without further description) have also been found in I. persulcatus collected in Moldova [82].

\section{Anaplasma platys}

The probable vector of $A$. platys in Europe is $R$. sanguineus. Experimental transmission has not been achieved [83]. Nevertheless, molecular studies have detected $A$. platys DNA in $R$. sanguineus ticks, which suggested that these ticks act as the vector for $A$. platys [84].

\section{Are there other routes of transmission for these infections in dogs?}

Outside the European continent (on which this guideline is focused), other species of ticks have been shown to be responsible for the transmission of E. canis [85]. However, to date, $R$. sanguineus appears to be the main vector for this pathogen.

In general, another route of transmission is through blood transfusion. Due to the potential transmission of these pathogens via infected blood, screening canine blood products for bacterial DNA with a polymerase chain reaction (PCR) assay is recommended in highly endemic areas to ensure the safety of blood products [86]. This route of transmission has been described for E. canis [69], A. phagocytophilum [87-89], and A. platys [90].

\section{Are Ehrlichia and Anaplasma species present in dogs in Europe able to affect other hosts? Ehrlichia canis}

Other wild canids (foxes, wolves, jackals) can become infected with E. canis [91-93]. However, experimental infection has only been reproduced in dogs. In addition, E. canis-like DNA was claimed to be detected in cat samples with PCR [94]. Moreover, several studies reported the presence of $E$. canis DNA in cats and wild felids from Brazil and Portugal [95-97]. However, to the best of our knowledge, E. canis has not been isolated from cats or other felids to date.

\section{Anaplasma phagocytophilum}

Anaplasma phagocytophilum can infect humans and several animals other than dogs, including cats, sheep, goats, cows, equines, rodents, roe deer, deer, other wild mammals, and birds [98-100].

\section{Anaplasma platys}

Anaplasma platys DNA was also recently found in cats in non-European continents [101,102].

\section{What is the public health importance of $E$. canis, A. phagocytophilum, and A. platys? Ehrlichia canis}

An organism closely related to E. canis has been described in humans in Venezuela [103]. To date, it is not considered an agent with important zoonotic potential.

\section{Anaplasma phagocytophilum}

Anaplasma phagocytophilum has important zoonotic potential, because humans can acquire the infection through a bite from a tick infected with the pathogen. Anaplasma phagocytophilum causes human granulocytic anaplasmosis, a febrile illness that closely resembles the disease in dogs. After infection (1-2 weeks), a syndrome frequently occurs of malaise, lowback pain, fever, and/or gastrointestinal disorders. Other, less frequent symptoms include arthralgia, lymphadenomegaly, conjunctivitis, dysuria, and peripheral edema $[104,105]$. 
The first infection by $A$. phagocytophilum in humans was described by Bakken et al in 1994 in the USA [106]. After that description, numerous human cases from different European countries were described [107]. Dogs may act as sentinels for human exposure, because infected ticks on their coats may travel to humans. Blood from infected dogs should be handled with caution $[107,108]$.

\section{Anaplasma platys}

Anaplasma platys DNA was recently detected in two family members in the USA [109] and two women from Venezuela [110].

Other Ehrlichia/Anaplasma spp. that have not been described in Europe can also infect humans. Ehrlichia ewingii has been described as a cause of infection in immune-suppressed patients [111], but there is no evidence of direct or tick-mediated transmission from dogs to human beings. Ehrlichia ruminantium, which typically infects wild ruminants, is also able to cause a disease in dogs [112] and humans [112,113]. Ehrlichia chaffeensis is the etiologic agent of human monocytic ehrlichiosis [99]. Amblyomma americanum acts as a vector for E. chaffeensis in the USA. Its hosts include white-tailed deer, goats, domestic dogs, red foxes, and birds. This Ehrlichia sp. has also been described in dogs [114,115], and DNA of E. chaffeensis has been found in ticks collected from dogs [116]. Finally, it has been shown that $E$. muris can infect both humans and dogs $[117,118]$.

\section{Is there a breed, age, or sex predisposition for canine ehrlichiosis or anaplasmosis? \\ Ehrlichia canis}

All breeds are prone to CME. However, German Shepherd dogs and Siberian Huskies are predisposed to develop more severe clinical signs of ehrlichiosis; therefore, these breeds have a worse prognosis $[119,120]$. This fact was corroborated in experimental studies, which showed that the cell-mediated immune response to a challenge with E. canis was reduced in German Shepherd dogs compared to Beagle dogs [119].

Canine ehrlichiosis may appear at any age. No sex predisposition has been detected in the development of CME. Some studies have found higher seropositivity in males, but this may be explained by a higher exposure to vectors than females, due to behavioral characteristics [121]. Similarly, in epidemiological studies, higher seropositivity rates were found in older dogs [121-123]; this observation may be attributed to a higher probability of exposure to E. canis as the dog ages, rather than an increase in susceptibility with age.

\section{Anaplasma phagocytophilum}

No breed predisposition has been confirmed for $A$. phagocytophilum infections. In a few studies, Retriever breeds were overrepresented; however, this might reflect the popularity of taking these dogs along for outdoor activities [124]. No sex or age predisposition has been documented for clinical cases. Older dogs were more often seropositive compared to younger dogs, probably due to an increased opportunity for exposure over time $[46,55]$.

\section{Anaplasma platys}

No breed, age, or sex predisposition has been described for A. platys infections.

\section{What stages of disease can be identified during infections with Ehrlichia and/or Anaplasma spp. in dogs? \\ Ehrlichia canis}

Following an incubation period of 1 to 3 weeks, three typical phases of the disease may develop sequentially: acute, subclinical, and chronic [2,125]. The acute phase can last 2 to 4 weeks; then, clinical signs may vary or disappear spontaneously, even without treatment. However, some dogs that show clinical improvement may remain persistent subclinical carriers for months and years [126]. The subclinical phase follows the acute stage. Dogs in this stage present no clinical signs; therefore, they may not seem to require veterinary attention. However, when screened for hematological abnormalities, these dogs may have subnormal platelet concentrations [127]. Some, but not all infected dogs may advance to a chronic phase. In the chronic phase, the clinical signs are more severe. Unfortunately, the acute and chronic phases are not always easy to distinguish in clinical practice, because many of the clinical signs are similar. A complete blood count and bone marrow aspiration may assist in diagnosing the chronic severe form of the disease. Dogs in the chronic phase exhibit bone marrow hypoplasia and severe pancytopenia [128]. No studies have fully elucidated the different responses of dogs to infection or the factors that induce some dogs to develop the chronic severe form of the disease.

\section{Anaplasma phagocytophilum}

The incubation period for an A. phagocytophilum infection lasts 1 to 2 weeks. Thereafter, the dog may develop a self-limiting febrile illness [87]. The main difference between $A$. phagocytophilum and E. canis is that most A. phagocytophilum cases present in the acute stage of the disease. Indeed, most dogs naturally infected with $A$. phagocytophilum probably remain healthy, as indicated by the high number of healthy seropositive dogs relative to dogs with the clinical disease [46]. The extent to which $A$. phagocytophilum can persist in tissues and contribute to subclinical/chronic disease manifestations in dogs has been a controversial issue [129].

Three dogs experimentally inoculated with $A$. phagocytophilum were monitored for 4 to 6 months to determine 
whether the organisms persisted. Rickettsial DNA was detected intermittently in two dogs, when PCR was performed on blood samples throughout the study [129].

\section{Anaplasma platys}

The incubation period for an $A$. platys infection is similar to that of an A. phagocytophilum infection (1 to 2 weeks). After that, alternate periods of thrombocytopenia and fever are observed, which appear and disappear cyclically every 1-2 weeks [130].

After an experimental inoculation of dogs with $A$. platys, parasitized platelets were detected in the peripheral blood after 8 to 15 days. The dogs developed severe thrombocytopenia within 7 days post inoculation [90]. After a reduction in the number of circulating bacteria, the platelet concentration increased within 3-4 days. These episodes of bacteremia and thrombocytopenia occurred at 1-2 week intervals. Chronic infection is associated with low-level bacteremia and mild thrombocytopenia, which may reflect a process where the host attempts to adapt to the $A$. platys infection [131].

\section{What clinical signs are associated to Ehrlichia spp. and Anaplasma spp. infections in dogs? Ehrlichia canis}

Clinical signs of an E. canis infection can be variable, depending on the strain, the immune response of the $\mathrm{dog}$, and the presence of concomitant infections with other tick- or flea-borne pathogens. It must be kept in mind that some dogs may not show clinical or laboratory signs associated with an Ehrlichia infection, and others may show severe signs. In general, $E$. canis seems to cause more severe clinical signs than anaplasmosis $[3,35,87,120,124,132-142]$.

Clinical signs of ehrlichiosis can vary, and it may include nonspecific signs, like fever, weakness, lethargy, anorexia, lymphadenomegaly, splenomegaly, hepatomegaly, or weight loss. Other signs have also been described, including vomiting, diarrhea, pain, exercise intolerance, edema (in hind legs, tail, or scrotum), cough and/or dyspnea (associated with pneumonia), serous or mucopurulent oculonasal discharge, abortion or neonatal death, and skin ulcers. Although some older studies have included lameness, due to polyarthritis, as a sign of CME $[143,144]$, no evidence-based studies have supported this sign. Therefore, in cases of lameness and/or polyarthritis in dogs infected with E. canis, it is advisable to rule out coinfections with other pathogens, such as $A$. phagocytophilum or B. burgdorferi.

Common clinical signs of ehrlichiosis include pale mucous membranes, due to anemia, epistaxis, petechiae, ecchymoses, prolonged bleeding during estrus, hematuria or melena associated with thrombocytopenia, thrombocytopathy, or vasculitis. Ocular signs are also common in
CME. The most common are anterior uveitis, corneal opacity, hyphema, retinal vessel tortuosity, chorioretinal lesions, subretinal hemorrhage, retinal detachment, or blindness. Neurological signs are less commonly described (typically secondary to meningitis).

\section{Anaplasma phagocytophilum}

The most common clinical signs of $A$. phagocytophilum are non-specific; they include lethargy, inappetence/anorexia, and fever. Other findings are pale mucous membranes, a tense abdomen, and gastrointestinal signs (vomiting/diarrhea). Lameness may result from secondary immune-mediated (neutrophilic) polyarthritis. Mildly enlarged lymph nodes, tachypnea, and surface bleeding (petechiae, melena, epistaxis) may occur. Rare signs include collapse, mild cough, scleral injection, uveitis, limb edema, and polydipsia/polyuria [145-151]. It is controversial whether central nervous system signs are associated with this infection [152-154]. In a few cases, an association was suggested between steroid-responsive meningitis/arteritis and A. phagocytophilum infection [155]. A. phagocytophilum infection may trigger some immunopathies, such as immune-mediated thrombocytopenia/ anemia. Splenomegaly diagnosed with radiography and ultrasonography is a very common finding [147].

\section{Anaplasma platys}

Clinical signs of $A$. platys infection have been described both experimentally and in naturally infected dogs in Greece, Spain, Portugal, and Israel. These signs included fever, lethargy, anorexia, weight loss, pale mucous membranes, petechiae, nasal discharge, and lymphadenomegaly. Furthermore, single case studies have described bilateral uveitis and epistaxis. However, not all studies used PCR to exclude co-infections with other vectortransmitted diseases that produce the same clinical signs $[54,62,63,66,146,156-158]$.

\section{What abnormal laboratory findings can be found in dogs with ehrlichiosis and/or anaplasmosis?}

Abnormal laboratory findings in canine ehrlichiosis or anaplasmosis are variable and nonspecific. However, the most common finding in ehrlichiosis and anaplasmosis is thrombocytopenia; this finding should alert clinicians. Other common abnormal laboratory findings are shown in Table 4 [54,147,148,159].

\section{Is microscopic evaluation of a blood smear or another tissue sample useful for the diagnosis of ehrlichiosis and anaplasmosis?}

The diagnostic usefulness of evaluating a blood smear depends on the pathogen species that has infected the dog. 
Table 4 Laboratory abnormal findings in ehrlichiosis caused by Ehrlichia canis and anaplasmosis caused by Anaplasma platys and Anaplasma phagocytophilum

\begin{tabular}{|c|c|c|}
\hline Clinical disease & Species & Laboratory abnormal findings \\
\hline \multirow[t]{17}{*}{ Canine monocytyc ehrlichiosis } & E. canis & $\begin{array}{l}\text { - Mild to moderate normocytic normochromic } \\
\text { non regenerative anemia }\end{array}$ \\
\hline & & - Neutropenia \\
\hline & & - Neutrophilia \\
\hline & & - Lymphopenia \\
\hline & & - Monocytosis \\
\hline & & - Granular lymphocytosis (uncommon) \\
\hline & & - Thrombocytopenia \\
\hline & & - Thrombocytopathy \\
\hline & & $\begin{array}{l}\text { - Pancytopenia: medullary hypoplasia or aplasia } \\
\text { (chronic forms, } 15-20 \% \text { of clinical cases) }\end{array}$ \\
\hline & & - Hyperproteinemia \\
\hline & & - Hyperglobulinemia \\
\hline & & • Hypergammaglobulinemia, usually polyclonal \\
\hline & & - Hypoalbuminemia \\
\hline & & - Proteinuria \\
\hline & & - Renal azotemia \\
\hline & & - Mild increase in hepatic enzymes (ALT, ALP) \\
\hline & & - Mononuclear or neutrophilic pleocytosis \\
\hline \multirow[t]{11}{*}{ Canine granulocytic anaplasmosis } & A. phagocytophilum & $\begin{array}{l}\text { - Non regenerative mild to moderate normocytic } \\
\text { normochromic anemia }\end{array}$ \\
\hline & & - Regenerative anemia (rare) \\
\hline & & - Lymphopenia \\
\hline & & $\begin{array}{l}\text { - Neutropenia, neutrophilia (sometimes left shift) or } \\
\text { normal neutrophil concentration }\end{array}$ \\
\hline & & - Thrombocytopenia \\
\hline & & - Hyperglobulinemia \\
\hline & & - Hypoalbuminemia \\
\hline & & - Increased ALP \\
\hline & & - Mild hyperbilirubinemia \\
\hline & & - Neutrophilic inflammation in synovial fluid \\
\hline & & $\begin{array}{l}\text { - Sometimes direct Coombs' test/platelet-bound } \\
\text { antibody test positive }\end{array}$ \\
\hline \multirow[t]{4}{*}{ Canine thrombocytotrophic anaplasmosis } & A. platys & - Thrombocytopenia \\
\hline & & $\begin{array}{l}\text { - Non regenerative mild to moderate normocytic } \\
\text { normochromic anemia }\end{array}$ \\
\hline & & - Hyperglobulinemia \\
\hline & & • Hypoalbuminemia \\
\hline
\end{tabular}

\section{Ehrlichia canis}

It is rare to detect an E. canis morula (an aggregate of E. canis organisms; Figure 2) in a blood smear. It occurs in about $4-6 \%$ of clinical cases [160]. The highest likelihood of detecting morulae can be achieved by performing a buffy coat smear [160]. Because the direct detection method has low sensitivity, further diagnostic tests must be conducted, such as serology or molecular techniques (PCR). The highest rates of detecting morulae (50\%) seem to be achieved when lymph node aspirates are examined by expert cytologists that evaluate a large number of oil immersion fields $[160,161]$.

\section{Anaplasma phagocytophilum}

The direct blood smear detection method seems to have higher sensitivity for detecting $A$. phagocytophilum than 


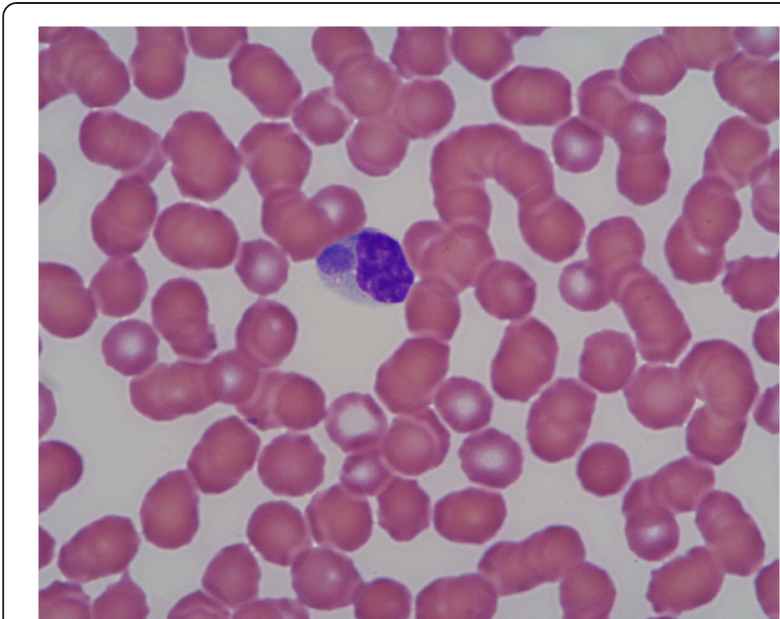

Figure 2 Microscopic image of a morula of Ehrlichia canis in the cytoplasm of a monocyte (x100).

for detecting E. canis in dogs. Morulae can be observed in neutrophils in up to $60 \%$ of clinical cases [147] (Figure 3). In experimentally infected dogs, morulae appear as early as 4 days after inoculation and persist for 4-8 days [129]. However, the morulae cannot be distinguished from those of other Ehrlichia spp. that infect neutrophils (e.g., Ehrlichia ewingii); therefore, the finding should be confirmed by PCR in areas where both organisms are likely to occur.

\section{Anaplasma platys}

The method of detecting morulae in platelets during an A. platys infection also appears to have a low sensitivity (Figure 4) [57], but some studies suggest that this method may have higher sensitivity during the early phase of the infection [162]. It was recently reported that $A$.

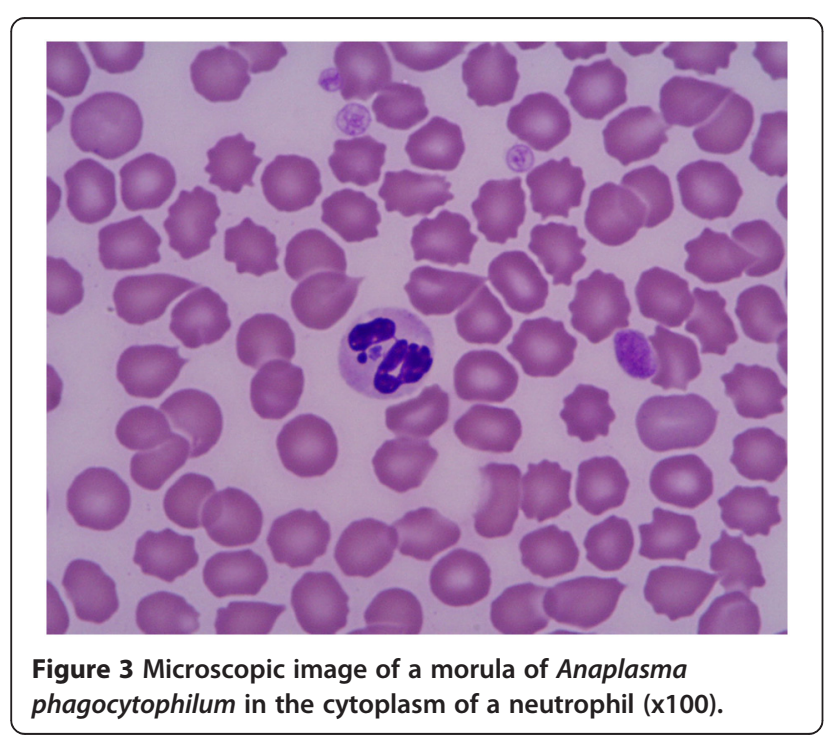

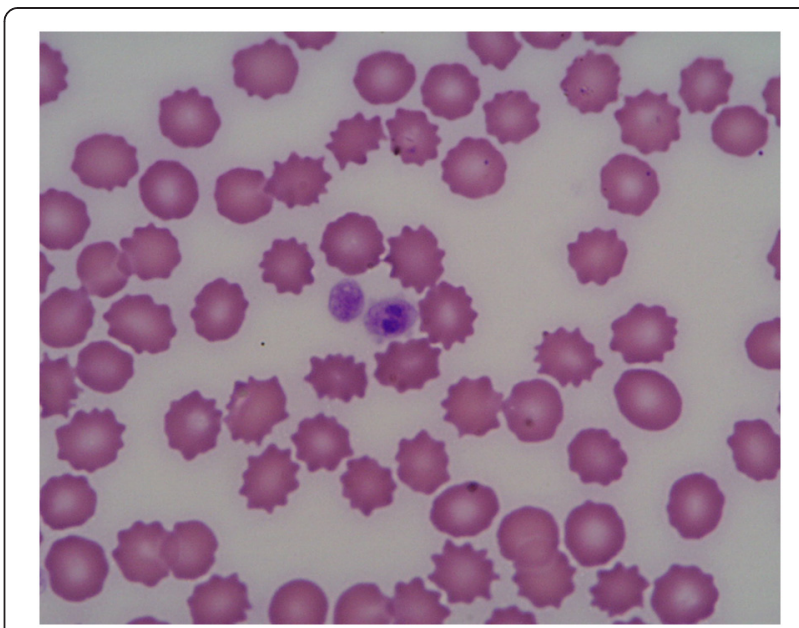

Figure 4 Microscopic image of a morula of Anaplasma platys in a platelet $(x 100)$.

platys were found in megakaryocytes [163], but the sensitivity of bone marrow cytology remains to be evaluated.

What serological techniques can be used in the diagnosis of ehrlichiosis and/or anaplasmosis?

Ehrlichiosis and/or anaplasmosis can be diagnosed with the IFAT or ELISA [142,164,165]. These tests require specific equipment and trained technicians. One of the advantages of these tests is that they allow determination of antibody levels and their changes over time. Therefore, it is important to conduct quantitative serologic tests and to determine either the final antibody titer with the IFAT or the optical density with the ELISA for a quantitative evaluation (negative, low, or high signals). Quantitative laboratory techniques are more sensitive and specific than rapid tests [164]. Some commercial inhouse dot-ELISA kits are qualitative, and show only a positive or negative result, without providing the dog's antibodies levels. Other dot-ELISA kits are semiquantitative and provide some information on antibody levels. However, an accurate, reliable serological diagnosis is limited by the lack of standardization among different diagnostic laboratories and tests.

\section{How should we interpret a positive serologic result for Ehrlichia and/or Anaplasma?}

A positive serologic result indicates a past or current infection, but it does not always denote an ongoing disease condition. A single positive titer result may only reflect a past infection that may be resolved, because antibody titers may persist for several months or years $[46,90,126]$. Moreover, seroprevalence is high in endemic areas. In dogs naturally infected with $E$. canis, some authors have found that animals with high IFAT titers were more likely to show PCR positivity than negativity; this finding 
suggested that there may be a relationship between antibody titer and active infection [166]. Nevertheless, this information must be confirmed. We suggest that suspected cases should be evaluated based on the performance of two or more serological tests conducted in 2-4 weeks intervals. This approach can provide information on antibody kinetics (an increase, no change, or a decrease), which may point to the current status of infection. It has been suggested that a four-fold increase in IgG antibodies over time can be taken as evidence of an ongoing infection [165]. Recent research has suggested that the combination of serology and PCR was preferable for the diagnosis of Ehrlichia and Anaplasma spp. infections [167]. Presently, we recommend performing molecular tests to support any positive serological case, because the presence of bacterial DNA is a sign of active infection.

\section{Could a seronegative dog be infected with Ehrlichia and/ or Anaplasma spp.?}

A dog can be seronegative, despite harboring an infection, with some species of Ehrlichia or Anaplasma. This is particularly common during the incubation period and in the early stages of the acute disease, when bacterial loads are low, for example:

- In the case of E. canis, antibody production typically does not occur before 12 -14 days post-infection [126,168].

- After experimentally infecting dogs with $A$. phagocytophilum, IgG antibodies may first be detectable 8 days after the initial exposure and 2 to 5 days after the appearance of morulae [129].

- After experimentally infecting dogs with A. platys, antibodies were first detected on day 16 [90].

Consequently, seroconversion can be used as a serologic technique to corroborate signs that suggest an acute infection with Ehrlichia or Anaplasma. Thus, an initial quantitative serology is conducted to detect acute antibody levels, when the dog shows clinical signs and/ or abnormal laboratory findings; then, another quantitative serology is conducted to detect convalescent antibody levels after 2-4 weeks. Positive antibody levels in the convalescent stage confirm the infection for some species of Ehrlichia and/or Anaplasma at disease onset. It should be noted that the administration of doxycycline will take effect over days and weeks; therefore, it will have no impact on the production of antibodies or the seroconversion [90,168-171].

\section{Do serological cross reactions exist among E. canis,} A. phagocytophilum, and A. platys?

It is generally accepted that no important cross reaction exists between Ehrlichia and Anaplasma. However, a potential cross reaction has been described between E. canis and A. phagocytophilum, particularly when one of the pathogens is present at very high titers or when the follow up is prolonged $[37,165]$. Apparently, there is no serological cross reaction between $E$. canis and A. platys; however, only a few, limited serologic studies have investigated this possibility [172].

When antibodies cross-react with more than one antigen/pathogen, the antibody titers that are highest indicate the most probable infecting pathogen in the dog [37]. However, a cross reaction was described between A. phagocytophilum and A. platys [37,173]. Moreover, A. phagocytophilum might cross react with other nonehrlichial species (e.g., Coxiella burnettii) [54,145].

As serological cross reactions may occur between different Ehrlichia and Anaplasma species, the serology should be complemented with molecular techniques, such as PCR and DNA sequencing.

\section{Why is a polymerase chain reaction assay useful in the diagnosis of these diseases?}

PCR is very useful in diagnosing these infectious diseases for several reasons. First, PCR detection is more sensitive than a direct microscopic examination. Second, the detection of DNA for a specific pathogen in a clinical setting should be considered evidence of an active infection. Third, real-time PCR permits quantification of bacterial loads. Finally, PCR allows one to investigate specific gene fragments after amplification. Sequencing the gene fragment/s amplified by PCR may reveal the identification of the specific Ehrlichia/Anaplasma species that infected the dog.

Real-time PCR assays that were developed for detecting infections of Ehrlichia or Anaplasma in peripheral blood have provided high sensitivity, similar to the sensitivity previously obtained with splenic samples $[169,174]$. Several third-party laboratories provide various PCR assays for detecting Ehrlichia and/or Anaplasma spp. However, the results depend on the experience and quality of the laboratory. The use of non-specific primers and low annealing temperatures in some PCR assays can result in non-specific amplification; thus, the evaluation may provide misleading, false-positive results.

Finally, it must be kept in mind that false-negative results can also occur due to the absence of pathogens in the sample. For example, bacteremia may be intermittent in some dogs or in specific diseases (e.g., A. platys infection); it may be present below the minimal detection level of the assay $[174,175]$; or it may be absent, due to previous administration of antibiotics, such as doxycycline. Therefore, a negative PCR result should be interpreted as "no detection of the tested pathogenDNA in the sample", rather than "the sample is free of the tested pathogen". Thus, to improve the usefulness 
of PCR and obtain as much information as possible from the results, it is important to submit samples to reliable laboratories and to assess the results in combination with an evaluation of antibody titers, clinical signs, and abnormal laboratory findings.

\section{What samples should be chosen to perform a molecular} diagnosis of Ehrlichia and/or Anaplasma spp. infections? The sample of choice for a PCR assay is peripheral blood, buffered with EDTA. Some studies have suggested that splenic aspirates seem to be optimal specimens for the diagnosis of E. canis infections based on PCR [176]. When microscopic examination reveals structures suggestive of morulae in the cytoplasm of neutrophils or mononuclear cells in any tissue or fluid, PCR can be used to corroborate the diagnosis.

\section{Are coinfections common in dogs infected with Ehrlichia and/or Anaplasma spp.?}

Coinfections with Ehrlichia and/or Anaplasma spp. are common, because some species are transmitted in the same arthropod vector [145,177]. Accordingly, coinfection of $E$. canis with $A$. platys should occur frequently.

Currently, many other vector-borne diseases have been shown to coexist in the same dog, including other tickborne pathogens (Babesia and Hepatozoon spp.), Culicidae mosquito-borne pathogens (Dirofilaria and other filariae), sand fly-borne pathogens (Leishmania infantum) [33,162], and even intestinal parasites [178]. In the Mediterranean basin, the most common coinfecting agents are L. infantum and Babesia spp. Less common are coinfections with Hepatozoon spp.

Due to the shared arthropod vectors and/or concurrent exposure to multiple vector-carrying ticks, co-infections may occur with other tick-borne pathogens (e.g., Borrelia, Bartonella, Rickettsia, Babesia, and arboviral spp.), which can complicate the clinical picture [179]. Because Borrelia burgdorferi and $A$. phagocytophilum are transmitted by the same ixodid tick species, coinfections with these two pathogens are frequently detected. Moreover, the two organisms may enhance one another's pathogenicity [180]. In northern California, dogs that are seroreactive to A. phagocytophilum were 18 times more likely to be seropositive for Bartonella vinsonii subs. berkhoffii than dogs seronegative for A. phagocytophilum [181].

\section{What is the clinical significance of a coinfection during the course of the disease?}

Coinfections tend to worsen some conditions and mask others, which could complicate the diagnosis [131]. Most vector-borne diseases have the special feature of causing similar clinical signs and abnormal laboratory findings in dogs (e.g., epistaxis and uveitis are signs that can be due to ehrlichiosis and/or leishmaniosis). This similarity complicates the diagnosis and increases the list of differential diagnoses. In one study, a coinfection with CME and Leishmania sp. delayed clinical improvement compared to dogs with either CME or leishmaniosis alone [182]. In another study, more clinical signs were noticed in dogs with dual infections (E. canis and L. infantum), which supported the notion that the pathogens may have synergistic pathological effects [183]. Furthermore, the occurrence of $A$. platys together with other infectious agents (e.g., E. canis, Babesia vogeli, or Rickettsia conorii) may potentiate the clinical disease and the laboratory abnormalities $[54,66,90]$.

Therefore, when an infection of one specific species is diagnosed, a comprehensive work-up is necessary to rule out coinfections with other vector-borne pathogens [177].

\section{What is the treatment of choice for Ehrlichia spp. and Anaplasma spp. infections? Ehrlichia canis}

CME is usually successfully treated with antibiotics that belong to the tetracycline family. The treatment of choice is doxycycline at $5 \mathrm{mg} / \mathrm{kg}$ twice daily or $10 \mathrm{mg} / \mathrm{kg}$ once daily for 4 weeks. This regime guarantees a complete response in the majority of cases $[125,168,176]$. Some reports described experimentally infected dogs that remained infected and became subclinical carriers after shorter treatments with doxycycline, even at the recommended doses $[125,166,170]$. Therefore, the more prolonged treatment of 4 weeks is recommended.

Although clinical improvement is achieved in most cases, it can be difficult to ensure treatment effectiveness regarding the total elimination of Ehrlichia spp. in naturally infected dogs. The clinician should not target seronegativity with treatment, but rather, negative PCR results $[6,142,166,168]$.

Doxycycline, unlike other tetracyclines, does not seem to cause enamel discoloration in puppies. Moreover, one of the most common side effects of tetracyclines, vomiting, can be eliminated by splitting the antibiotic dose into two half-doses every $12 \mathrm{~h}$ (q12h) or by administering the antibiotic after feeding. When the dog has liver problems, the use of doxycycline should be reconsidered. In any case, liver function tests should be performed before and during treatment; when liver parameters increase, the treatment regime should be stopped $[6,142,166,168]$.

Other drugs have been historically used for treating CME. Chloramphenicol has been used in dogs under 1 year of age, but its use is not recommended when doxycycline is available. Imidocarb dipropionate has also been described as a potential treatment for ehrlichiosis in dogs $[171,184,185]$. Recent studies performed in vitro and in experimentally infected dogs showed that imidocarb dipropionate was not effective against $E$. canis $[186,187]$. It should only be used in cases of co-infection 
with Babesia canis or Hepatozoon canis. Other antibiotics, such as rifampicin or levofloxacin, have been effective in in vitro studies [188]. However, recent studies have shown that, in experimental infections, rifampicin contributed to improving laboratory findings, but it was not effective in eliminating the infection [189].

\section{A. phagocytophilum}

Doxycycline (for 2-3 weeks) at the dosage described above for $E$. canis is apparently effective in treating $A$. phagocytophilum infections. However, several parameters remain to be established, including the most effective or optimal dose; the length of doxycycline treatment; and the value of adding other antibiotics $[145,146,174,175,190]$. Rifampin and levofloxacin have also shown in vitro effects against $A$. phagocytophilum [190]. Chloramphenicol has been mentioned as an alternative for treating puppies [191].

When dogs with circulating Anaplasma organisms have moderate to severe clinical disease or do not rapidly respond to doxycycline therapy, they should probably be tested for other tick-borne diseases [146].

\section{Anaplasma platys}

Anaplasma platys infections can be treated with tetracyclines (e.g., doxycycline $5-10 \mathrm{mg} / \mathrm{kg}$ q12-24h for $8-10$ days). Alternatively, they can be treated with enrofloxacin at $5 \mathrm{mg} / \mathrm{kg}$, q12h for 14-21 days [131,192].

\section{Are there other supportive therapies that could be used} for ehrlichiosis and/or anaplasmosis?

In severe or chronic ehrlichiosis and/or anaplasmosis, other therapeutic agents or treatments may be needed, particularly for $E$. canis infections. For cases with hemorrhage or organic lesions, the dog may require admission to a hospital for a more intensive treatment. In general, according to the seriousness determined in the clinic, dogs may need blood transfusions when the packed cell volume (PCV) is very low; fluid therapy when dehydration or secondary kidney disease is present; or antipyretic and analgesic drugs $[138,142,146]$.

In some cases of chronic ehrlichiosis, when aplasia of all cell lines occurs, other treatments have been used. For example, growth factors, like granulocyte colony stimulating factor or erythropoietin have been used; however, scientific evidence of effectiveness is scarce. One case of chronic ehrlichiosis was treated successfully with a combination of hematopoietic growth factors, low dose vincristine, doxycycline, and glucocorticoids [193].

\section{Is it necessary to use steroids for treating ehrlichiosis} and/or anaplasmosis?

Treatment of ehrlichiosis or anaplasmosis should not be initiated with glucocorticoids combined with antibiotics.
Steroids should only be considered when no satisfactory response is noticed, or when immune-mediated complications arise. Ehrlichia and Anaplasma species may mediate an immune response, typically indicated by hemolytic anemia, thrombocytopenia, uveitis, glomerulonephritis, vasculitis, etc. In those cases, treatment with glucocorticoids (usually prednisone or prednisolone) may be indicated; doses of prednisone should range from 0.5 to $2 \mathrm{mg} /$ $\mathrm{kg} / \mathrm{day}$, and the treatment duration should vary according to the type and seriousness of the associated immunemediated condition [133,147,152,194-196]. However, the use of immunosuppressive glucocorticoids for treatment of secondary immune-mediated diseases must be considered very carefully. Of note, the administration of immunosuppressive doses of glucocorticoids or other drugs to subclinically infected dogs may result in the reemergence of bacteremia, although the dog may not show clinical signs $[6,129,142,174,175]$.

\section{What is the expected clinical response following the treatment of ehrlichiosis and/or anaplasmosis?}

Doxycycline is an effective drug against ehrlichiosis and/ or anaplasmosis in dogs $[120,145,146]$. When dogs are treated in the acute phase of ehrlichiosis and anaplasmosis, they improve quickly, within $24-48 \mathrm{~h}$, and their prognosis is good when the whole course of therapy is administered [120,147,197].

However, the prognosis of dogs with the chronic severe form of ehrlichiosis is grave [120,197]. Shipov and colleagues (2008) investigated prognostic indicators for mortality and survival in canine ehrlichiosis [198]. They found that pronounced pancytopenia (white blood cells $[\mathrm{WBC}]<4 \times 10^{3} / \mu \mathrm{L} ; \mathrm{PCV}<25 \%$; and platelet concentration $[\mathrm{PLT}]<50 \times 10^{3} / \mu \mathrm{L}$ ) was a risk factor for mortality. In that study, they found that severe leucopenia $\left(\mathrm{WBC}<0.93 \times 10^{3} / \mu \mathrm{L}\right)$, severe anemia $(\mathrm{PCV}<11.5 \%)$, prolonged activated partial thromboplastin time (APTT $>18.25 \mathrm{~s})$, and hypokalemia $(\mathrm{K}<3.65 \mathrm{mmol} / \mathrm{L})$ could each predict mortality with a probability of $100 \%$. Conversely, a WBC $>5.18 \times 10^{3} / \mu \mathrm{L}, \mathrm{PLT}>89.5 \times 10^{3} / \mu \mathrm{L}$, $\mathrm{PCV}>33.5 \%$, APTT $<14.5 \mathrm{~s}$, or $\mathrm{K}>4.75 \mathrm{mmol} / \mathrm{L}$ could each predict survival with a probability of $100 \%$.

When the clinical response in canine ehrlichiosis or anaplasmosis is not rapid, or when clinical signs persist after treatment with doxycycline, the dog must be reexamined for other infectious diseases or diseases with similar clinical signs (neoplasia or immune-mediated diseases) $[6,142,146]$.

\section{How do abnormal laboratory findings evolve in dogs infected with ehrlichiosis/anaplasmosis after the treatment? Ehrlichia canis}

Laboratory abnormalities in canine ehrlichiosis typically resolve in dogs after treatment with acute disease. In 
general, both the complete blood count and the alterations in serum protein electrophoresis should normalize within 10-15 days after therapy initiation [6,142].

Chronic changes, such as mild or moderate hyperglobulinemia, anemia, or thrombocytopenia may persist as long as the infectious agent has not been completely eliminated, or when some other associated conditions exist [171]. In naturally infected dogs, despite evident clinical improvement, it is difficult to guarantee treatment effectiveness and complete elimination of the involved pathogens $[6,142]$. When the dog no longer produces specific antibodies to the pathogen, it can be assumed that complete elimination of the Ehrlichia species has been achieved [120].

Quantification of acute phase proteins in serum has been assessed for its value in monitoring and evaluating the prognosis of dogs with ehrlichiosis. Although quantification of acute phase proteins may be a useful indicator of the clinical stage, it has no predictive value for the final clinical outcome [199].

Finally, it must be recognized that prior infections with $E$. canis do not confer permanent immunity to dogs. Therefore, dogs can be re-infected with the same pathogen or with other species after re-exposure to infected ticks $[6,142]$.

\section{Anaplasma phagocytophilum}

Similar to canine ehrlichiosis, after treating anaplasmosis, laboratory alterations in the complete blood cell count and in serum protein electrophoresis should be resolved in most dogs [146,147].

\section{Anaplasma platys}

Thrombocytopenia in dogs infected with $A$. platys typically disappears around one week after starting therapy [192].

\section{How do antibody titers evolve following treatment? Ehrlichia canis}

Antibody titers may persist for months. Then, in most E. canis infections, they decrease gradually over 6-9 months post treatment. Sometimes, antibodies are no longer detectable at 12 months. However, frequently, some cases remain seropositive for several years after the treatment [194], particularly when starting with very high antibody titers [171].

\section{Anaplasma phagocytophilum}

Information regarding the persistence of $A$. phagocytophilum antibody titers is limited. However, some studies have described persistence of seropositivity for up to one year after the treatment [200].

\section{Anaplasma platys}

Information regarding antibody titers in dogs naturally infected with A. platys is scarce. A steady decline of antibody titers after therapy has been described in dogs experimentally infected with $A$. platys [90].

\section{Why is PCR useful after treatment?}

PCR testing, when conducted several weeks after termination of doxycycline treatment, allows clinicians to be more confident that the treatment has been effective and that the dog did not enter the subclinical stage $[6,142,146,186,201]$. Yet, it must be recognized that a negative PCR result does not guarantee that the animal is "free of infection" (see above).

There are two goals for performing PCR some weeks after the completion of treatment. One is to minimize the probability of obtaining false-negative results, due to antibiotic effects on bacteremia. The second is to minimize the chance of detecting DNA of dead pathogens that continue to circulate during the treatment period $[6,132,142,174,175]$.

In conclusion, PCR is useful for monitoring dogs treated for these diseases, because it can detect the presence of pathogen DNA, regardless of the serologic antibody titers. However, although this technique is more sensitive than serology in confirming an infection, its effectiveness may be limited for detecting pathogens in subclinically infected dogs, because the organisms may circulate intermittently in peripheral blood. Therefore, a PCR analysis should not be considered a definitive method for conclusively excluding subclinical infection in clinically normal dogs that remain seropositive after treatment $[6,142,145,146]$.

\section{Can canine ehrlichiosis and/or anaplasmosis be cured?}

In general, most acutely ill dogs infected with Ehrlichia or Anaplasma species heal after a specific, effective treatment of appropriate length. This finding has been corroborated with multiple clinical and experimental trials $[166,168,170]$. However, a recent work conducted with dogs experimentally infected with $E$. canis suggested that some dogs may remain persistently infected and may not eliminate the infection even after acceptable treatment [125].

\section{Can dogs be re-infected by Ehrlichia and/or Anaplasma spp.? \\ Ehrlichia canis}

Re-infections of canine ehrlichiosis are possible, because no persistent or effective immunity develops to defend against re-infection with these pathogens [120]. In most cases, after treatment, the dogs return to the habitat they lived in prior to the infection; therefore, their exposure to infected ticks remains feasible. When no proper tickcontrol measures are employed, and the dogs are reexposed, they can easily become re-infected. Moreover, mainly in cases of canine ehrlichiosis, it is difficult to 
distinguish a re-infection from recurrence of an established persistent subclinical condition [177].

\section{Anaplasma phagocytophilum}

It is not known whether a natural infection can provide long term protection against the development of clinical anaplasmosis. Re-infection following the therapeutic elimination of the organism has not been reported in dogs; however, in human medicine, one re-infection case was documented [202]. Conversely, horses have been shown to resist re-infection after recovery from an initial infection with A. phagocytophilum [200].

\section{Anaplasma platys}

The possibility of $A$. platys re-infections in dogs living in endemic areas and exposed to ticks has not been fully evaluated, but cannot be ruled out.

What prophylactic measures can be implemented to prevent infection by Ehrlichia and/or Anaplasma spp. in dogs?

The prevention of ehrlichiosis and/or anaplasmosis infections in dogs must be focused on tick control. Ticks of the $R$. sanguineus complex are mainly found indoors, but other populations of the tick may be common in gardens, pastures, and fields in the Mediterranean basin. Therefore, dogs may become infected with the most common tick present in infested private gardens or kennels, but also, whenever they are engaged in an activity that involves contact with natural green areas. Nevertheless, to prevent transmission, actions must focus mainly on:

- preventing dogs from becoming infested in the field, which is the source of peridomestic parasitism. This infestation can introduce ticks to indoor habitats (kennels, etc.), which will result in a large population, due to their high reproductive capacity.

- preventing dogs from becoming infested with ticks, even when they live in a peridomestic environment with abundant ticks. This objective is more difficult to achieve than the former, due to the high parasitism pressure that can arise from those populations of ticks [203].

To appropriately control tick infestations in dogs requires knowledge of tick seasonality. This seasonality is usually strict under natural conditions, and each stage of the life cycle of the tick follows the previous stage with regularity. However, these patterns can be lost in areas with large infestations in a peridomestic environment. Under those conditions, all stages can be active simultaneously, due to the presence of several infestations in the kennel.

Outdoor populations of $R$. sanguineus can be active and, therefore infest dogs, when the average temperature is $10-12^{\circ} \mathrm{C}$. Below this temperature, it is very rare that dogs acquire infestations from outdoor populations of that tick; consequently, during winter, it may be appropriate to reduce the treatment pressure against ticks. However, it must be noted that indoor populations of the ticks may be active year round, which adds extra risk for dogs living in kennels or dogs that spend time in dog day care centers. In Europe, tick control should be continuous between spring and autumn in areas where ticks are present. This pattern may vary according to the local weather and the historic weather particularities. Clearly, measures against $R$. sanguineus must follow extended schedules in the Mediterranean basin, because winters are shorter, and therefore, the periods of $R$. sanguineus activity are prolonged.

In the case of $I$. ricinus, the activation temperature for the ticks may be around $6^{\circ} \mathrm{C}$. Therefore, adequate measures of control should be strictly followed to limit contact of dogs with ticks in infested areas [72].

Various antiparasitic treatments are registered in Europe that have activity against ticks and can be prescribed for dogs [204]. The specific product can be selected according to the preferences of use (collar, pour-on, or spot on) and the therapeutic needs for each case. Some compounds, such as the pyrethroids or some preparations of diazinon, are registered as repellents.

Apart from appropriate epidemiological measures, the best prevention against dog tick infestation is based on the use of ectoparasiticides. In general, these are active molecules that act against ticks, and they must also provide some degree of appropriate control within a short period of time [205]. Rapid action could contribute to the elimination of attached ticks before they are able to transmit pathogens. To optimize efficacy, preventive chemicals must be applied at the recommended time intervals, based on the length of efficacy claimed by the manufacturer. Although knowledge may be lacking for some diseases, most tick-borne pathogens require 4 to $48 \mathrm{~h}$ to complete their development in the salivary gland and enter the bloodstream [100]. However, a recent report showed that transmission of $E$. canis can occur within shorter periods of time (e.g., 3 h) [71].

Are there vaccines available to prevent ehrlichiosis and/or anaplasmosis in dogs?

Currently, no commercial vaccines are available to protect against infections with $E$. canis, A. phagocytophilum, or A. platys. A recent study showed that an attenuated $E$. canis strain may serve as an effective future vaccine for CME [206].

\section{Conclusions}

Information on canine ehrlichiosis and anaplasmosis in Europe has significantly increased in the last few years. 
This guideline aimed to answer common questions of interest on the etiology, transmission, epidemiology, clinical signs, laboratory findings, diagnosis, therapy, and prophylaxis of infections caused by Ehrlichia and Anaplasma spp. This guideline contributes to the understanding of the current status of these diseases on the European continent. However, these pathogens are spreading to new niches, and reports have described infections in many countries where they were not detected previously.

\begin{abstract}
Abbreviations
ACVIM: American College of Veterinary Internal Medicine; CME: Canine monocytic ehrlichiosis; ELISA: Enzyme-linked immunosorbent assay; ENTRA group: Abbreviation in Spanish for "Grupo de Estudio de Enfermedades Transmitidas por Artrópodos" - Arthropod-Borne Disease Experts Group; ESCCAP: European Scientific Counsel of Companion Animal Parasites; IFAT: Immunofluorescent antibody test; PCR: Polymerase chain reaction; PCV: Packed cell volume; PLT: Platelet concentration; APTT: Prolonged activated partial thromboplastin time; q12h: Once every 12 hours; WBC: White Blood Cells.

\section{Competing interests}

Five authors of this guideline (AS, XR, GM, AEP and LSG) are members of the ENTRA group. The ENTRA group is supported by Merial Laboratorios (Spain), but it is a scientifically independent body.
\end{abstract}

\section{Authors' contributions}

$A S, X R, G M, A E P$, and LSG designed the initial structure of the guideline, and wrote the first version of the manuscript. BK reviewed the manuscript and made substantial contributions to the structure and content, particularly parts related to A. phagocytophilum infections. SH reviewed the manuscript and made substantial contributions to the structure and content, particularly parts related to E. canis and A. platys infections. AS participated as the coordinator of the group. All authors read and approved the final manuscript.

\section{Authors' information \\ About the ENTRA group \\ The ENTRA group (abbreviation in Spanish for "Grupo de Estudio de Enfermedades Transmitidas por Artrópodos" - Arthropod-Borne Disease Experts Group) is composed of Spanish veterinary scientists, whose careers have focused on research on arthropods and arthropod-borne diseases. The main goal of this group is to process and report the most significant information on this variety of diseases. This work is deemed useful for small animal veterinary practitioners. Based on those premises, the ENTRA group decided to publish a practical guideline regarding ehrlichiosis and anaplasmosis in dogs, given the high prevalence rates described in Spain and the multiple studies recently conducted on these diseases in that country. Subsequently, the group decided that this guideline could have greater relevance by broadening the scope to the European continent. Consequently, we invited other European scientists working on these diseases to participate in this project. This guideline was the result of a complete review of the literature. The experience of all the authors has been included, and a consensus among them was reached. \\ The questions included in this document are intended to address the most common concerns about these diseases, and we provided answers from a practical point of view. \\ The authors Member of ENTRA group are Ángel Sainz, Xavier Roura, Guadalupe Miró, Agustín Estrada-Peña and Laia Solano-Gallego.}

\section{Acknowledgements}

The authors would like to acknowledge Merial Laboratorios (Spain), the sponsor of the manuscript publication, and we extend special thanks to Marta León for providing assistance.

\section{Author details}

'Department of Animal Medicine and Surgery, Veterinary Clinic Hospital, Faculty of Veterinary Medicine, Universidad Complutense de Madrid, Madrid,
Spain. ${ }^{2}$ Hospital Clinic Veterinari, Universitat Autònoma de Barcelona, Barcelona, Spain. ${ }^{3}$ Department of Animal Health, Veterinary Clinic Hospital, Faculty of Veterinary Medicine, Universidad Complutense de Madrid, Madrid, Spain. ${ }^{4}$ Department of Animal Pathology, Faculty of Veterinary Medicine, University of Zaragoza, Zaragoza, Spain. ${ }^{5}$ Small Animal Clinic, Faculty of Veterinary Medicine, Freie Universität Berlin, Berlin, Germany. ${ }^{6}$ Koret School of Veterinary Medicine, The Hebrew University of Jerusalem, Rehovot, Israel. ${ }^{7}$ Departament de Medicina i Cirurgia Animal, Facultat de Veterinaria, Universitat Autònoma de Barcelona, Bellaterra, Spain.

Received: 29 June 2014 Accepted: 10 January 2015

Published online: 04 February 2015

\section{References}

1. Donatien A, Lestoquard F. Existence en Algerie d'une Rickettsia du chien. Bull Soc Pathol Exot. 1935;28:418-9.

2. Huxsoll DL, Hildebrandt PK, Nims RM, Walker JS. Tropical canine pancytopenia. J Am Vet Med Assoc. 1970;157(11):1627-32

3. Harvey JW, Simpson CF, Gaskin JM. Cyclic thrombocytopenia induced by a Rickettsia-like agent in dogs. J Infect Dis. 1978;137(2):182-8.

4. Madewell BR, Gribble DH. Infection in two dogs with an agent resembling Ehrlichia equi. J Am Vet Med Assoc. 1982;180(5):512-4.

5. Dumler JS, Barbet AF, Bekker CP, Dasch GA, Palmer GH, Ray SC, et al. Reorganization of genera in the families Rickettsiaceae and Anaplasmataceae in the order Rickettsiales: unification of some species of Ehrlichia with Anaplasma, Cowdria with Ehrlichia and Ehrlichia with Neorickettsia, descriptions of six new species combinations and designation of Ehrlichia equi and 'HGE agent' as subjective synonyms of Ehrlichia phagocytophila. Int J Syst Evol Microbiol. 2001;51(Pt 6):2145-65.

6. Neer TM, Breitschwerdt EB, Greene RT, Lappin MR. Consensus statement on ehrlichial disease of small animals from the infectious disease study group of the ACVIM. American College of Veterinary Internal Medicine. J Vet Intern Med. 2002;16(3):309-15.

7. Keysary A, Waner T, Rosner M, Warner CK, Dawson JE, Zass R, et al. The first isolation, in vitro propagation, and genetic characterization of Ehrlichia canis in Israel. Vet Parasitol. 1996;62(3-4):331-40.

8. Aguirre E, Sainz A, Dunner S, Amusategui I, Lopez L, Rodriguez-Franco F, et al. First isolation and molecular characterization of Ehrlichia canis in Spain. Vet Parasitol. 2004;125(3-4):365-72.

9. Shpynov SN, Fournier PE, Rudakov NV, Samoilenko IE, Reshetnikova TA Yastrebov VK, et al. Molecular identification of a collection of spotted Fever group rickettsiae obtained from patients and ticks from Russia. Am J Trop Med Hyg. 2006;74(3):440-3.

10. Spitalska E, Boldis V, Kostanova Z, Kocianova E, Stefanidesova K. Incidence of various tick-borne microorganisms in rodents and ticks of central Slovakia. Acta Virol. 2008;52(3):175-9.

11. Dongus H, Zahler M. Gothe R: The brown dog tick, Rhipicephalus sanguineus (Ixodidae), in Germany: an epidemiologic study and control measures]. Berl Munch Tierarztl Wochenschr. 1996;109(6-7):245-8.

12. Gothe R. [Ehrlichia canis infections of dogs in Germany. Epidemiology, diagnosis, therapy and prophylaxis]. Tierarztl Prax Ausg K Kleintiere Heimtiere. 1998;26(6):396-401.

13. Pusterla N, Pusterla JB, Deplazes P, Wolfensberger C, Muller W, Horauf A, et al. Seroprevalence of Ehrlichia canis and of canine granulocytic Ehrlichia infection in dogs in Switzerland. J Clin Microbiol. 1998;36(12):3460-2.

14. Hamel D, Silaghi C, Knaus M, Visser M, Kusi I, Rapti D, et al. Detection of Babesia canis subspecies and other arthropod-borne diseases in dogs from Tirana, Albania. Wien Klin Wochenschr. 2009;121 Suppl 3:42-5.

15. Perez Vera C, Kapiainen S, Junnikkala S, Aaltonen K, Spillmann T, Vapalahti O. Survey of selected tick-borne diseases in dogs in Finland. Parasit Vectors. 2014;7:285.

16. Pantchev N, Schaper R, Limousin S, Norden N, Weise M, Lorentzen L. Occurrence of Dirofilaria immitis and tick-borne infections caused by Anaplasma phagocytophilum, Borrelia burgdorferi sensu lato and Ehrlichia canis in domestic dogs in France: results of a countrywide serologic survey. Parasitol Res. 2009:105 Suppl 1:S101-14.

17. Hamel D, Silaghi C, Pfister K. Arthropod-borne infections in travelled dogs in Europe. Parasite. 2013;20:9.

18. Hamel D, Rohrig E, Pfister K. Canine vector-borne disease in travelled dogs in Germany-a retrospective evaluation of laboratory data from the years 2004-2008. Vet Parasitol. 2011;181(1):31-6. 
19. Menn B, Lorentz S, Naucke TJ. Imported and travelling dogs as carriers of canine vector-borne pathogens in Germany. Parasit Vectors. 2010;3:34.

20. Farkas R, Gyurkovszky M, Lukacs Z, Aladics B, Solymosi N. Seroprevalence of some vector-borne infections of dogs in Hungary. Vector Borne Zoonotic Dis. 2014;14(4):256-60.

21. Pennisi MG, Capri A, Solano-Gallego L, Lombardo G, Torina A, Masucci M. Prevalence of antibodies against Rickettsia conorii, Babesia canis, Ehrlichia canis, and Anaplasma phagocytophilum antigens in dogs from the Stretto di Messina area (Italy). Ticks Tick Borne Dis. 2012;3(5-6):315-8.

22. Trotta M, Fogliazza A, Furlanello T, Solano-Gallego L. A molecular and serological study of exposure to tick-borne pathogens in sick dogs from Italy. Clin Microbiol Infect. 2009;15 Suppl 2:62-3.

23. Torina A, Vicente J, Alongi A, Scimeca S, Turla R, Nicosia S, et al. Observed prevalence of tick-borne pathogens in domestic animals in Sicily, Italy during 2003-2005. Zoonoses Public Health. 2007;54(1):8-15.

24. Corrain R, Di Francesco A, Bolognini M, Ciucci P, Baldelli R, Guberti V. Serosurvey for CPV-2, distemper virus, ehrlichiosis and leishmaniosis in free-ranging dogs in Italy. Vet Rec. 2007;160(3):91-2.

25. Solano-Gallego L, Trotta M, Razia L, Furlanello T, Caldin M. Molecular survey of Ehrlichia canis and Anaplasma phagocytophilum from blood of dogs in Italy. Ann N Y Acad Sci. 2006;1078:515-8.

26. Cocco R, Sanna G, Cillara MG, Tola S, Ximenes L, Pinnaparpaglia ML, et al. Ehrlichiosis and rickettsiosis in a canine population of Northern Sardinia. Ann N Y Acad Sci. 2003;990:126-30.

27. Buonavoglia D, Sagazio P, Gravino EA, De Caprariis D, Cerundolo R, Buonavoglia C. Serological evidence of Ehrlichia canis in dogs in southern Italy. New Microbiol. 1995;18(1):83-6.

28. Cardoso L, Mendao C. Madeira de Carvalho L: Prevalence of Dirofilaria immitis, Ehrlichia canis, Borrelia burgdorferi sensu lato, Anaplasma spp. and Leishmania infantum in apparently healthy and CVBD-suspect dogs in Portugal-a national serological stud. Parasit Vectors. 2012;5:62.

29. Alexandre N, Santos AS, Nuncio MS, Sousa R, Boinas F, Bacellar F. Detection of Ehrlichia canis by polymerase chain reaction in dogs from Portugal. Vet J. 2009;181(3):343-4.

30. Bacellar F, Dawson JE, Silveira CA, Filipe AR. Antibodies against Rickettsiaceae in dogs of Setubal. Portugal Cent Eur J Public Health. 1995;3(2):100-2.

31. Mircean V, Dumitrache MO, Gyorke A, Pantchev N, Jodies R, Mihalca AD, et al. Seroprevalence and geographic distribution of Dirofilaria immitis and tick-borne infections (Anaplasma phagocytophilum, Borrelia burgdorferi sensu lato, and Ehrlichia canis) in dogs from Romania. Vector Borne Zoonotic Dis. 2012;12(7):595-604.

32. Volgina NS, Romashov BV, Romashova NB, Shtannikov AV. Prevalence of borreliosis, anaplasmosis, ehrlichiosis and Dirofilaria immitis in dogs and vectors in Voronezh Reserve (Russia). Comp Immunol Microbiol Infect Dis. 2013;36(6):567-74.

33. Miro G, Montoya A, Roura X, Galvez R, Sainz A. Seropositivity rates for agents of canine vector-borne diseases in Spain: a multicentre study. Parasit Vectors. 2013;6:117.

34. Couto CG, Lorentzen L, Beall MJ, Shields J, Bertolone N, Couto Jl, et al. Serological study of selected vector-borne diseases in shelter dogs in central Spain using point-of-care assays. Vector Borne Zoonotic Dis. 2010;10(9):885-8.

35. Tabar MD, Francino O, Altet L, Sanchez A, Ferrer L, Roura X. PCR survey of vectorborne pathogens in dogs living in and around Barcelona, an area endemic for leishmaniasis. Vet Rec. 2009;164(4):112-6.

36. Amusategui I, Tesouro MA, Kakoma I, Sainz A. Serological reactivity to Ehrlichia canis, Anaplasma phagocytophilum, Neorickettsia risticii, Borrelia burgdorferi and Rickettsia conorii in dogs from northwestern Spain. Vector Borne Zoonotic Dis. 2008;8(6):797-803.

37. Solano-Gallego L, Llull J, Osso M, Hegarty B, Breitschwerdt E. A serological study of exposure to arthropod-borne pathogens in dogs from northeastern Spain. Vet Res. 2006;37(2):231-44.

38. Sainz A, Amusategui I, Tesouro MA. Canine ehrlichiosis in the Comunidad de Madrid in central Spain. Ann N Y Acad Sci. 1998;849:438-40.

39. Sainz A, Delgado S, Amusategui I, Tesouro MA, Carmenes P. Seroprevalence of canine ehrlichiosis in Castilla-Leon north-west Spain. Prev Vet Med. 1996:29(1):1-7.

40. Batmaz H, Nevo E, Waner T, Senturk S, Yilmaz Z, Harrus S. Seroprevalence of Ehrlichia canis antibodies among dogs in Turkey. Vet Rec. 2001;148(21):665-6.

41. Kirtz B, Czettel B, Thum D, et al. Anaplasma phagozytophilum in einer österreichischen Hundepopulation: eine Prävalenz-Studie (2001-2006). Kleintierpraxis. 2007;52:562-8.
42. Barutzki D, De Nicola A, Zeziola M. Reule M: [Seroprevalence of Anaplasma phagocytophilum infection in dogs in Germany]. Berl Munch Tierarztl Wochenschr. 2006;119(7-8):342-7.

43. Jensen J, Simon D, Murua Escobar H, Soller JT, Bullerdiek J, Beelitz P, et al. Anaplasma phagocytophilum in dogs in Germany. Zoonoses Public Health. 2007:54(2):94-101.

44. Schaarschmidt-Kiener D, Müller W. Labordiagnostische und klinische Aspekte der caninen Anaplasmose und Ehrlichiose. Tierarztl Prax. 2007;35:129-36.

45. Krupka I, Pantchev N, Lorentzen L, Weise M, Straubinger RK. Tick-transmitted, bacterial infections in dogs: seroprevalences of Anaplasma phagocytophilum, Borrelia burgdorferi sensu lato and Ehrlichia canis in Germany. Prakt Tierarzt. 2007:88(10):776-88.

46. Kohn B, Silaghi C, Galke D, Arndt G, Pfister K. Infections with Anaplasma phagocytophilum in dogs in Germany. Res Vet Sci. 2011;91(1):71-6.

47. Barth C, Straubinger RK, Sauter-Louis C, Hartmann K. Prevalence of antibodies against Borrelia burgdorferi sensu lato and Anaplasma phagocytophilum and their clinical relevance in dogs in Munich, Germany. Berl Munch Tierarzt| Wochenschr. 2012;125(7-8):337-44.

48. de la Fuente J, Torina A, Naranjo V, Nicosia S, Alongi A, La Mantia F, et al. Molecular characterization of Anaplasma platys strains from dogs in Sicily, Italy. BMC Vet Res. 2006;2:24.

49. Torina A, Caracappa S. Dog tick-borne diseases in Sicily. Parassitologia. 2006;48(1-2):145-7.

50. Ebani V, Cerri D, Fratini F, Ampola M, Andreani E. Seroprevalence of Anaplasma phagocytophilum in domestic and wild animals from central Italy. New Microbiol. 2008;31(3):371-5.

51. Ebani W, Bertelloni F, Turchi B, Cerri D. Serological and molecular survey of Anaplasma phagocytophilum in Italian hunting dogs. Ann Agric Environ Med. 2013;20(2):289-92.

52. Berzina I, Matise I. Seroprevalence against Borrelia burgdorferi sensu lato and occurence of antibody co-expression with Anaplasma phagocytophilum in dogs in Latvia. Ir Vet J. 2013;66(1):9.

53. Skotarczak B, Adamska M, Rymaszewska A, Supron M, Sawczuk M. Maciejewska A: [Anaplasma phagocytophila and protozoans of Babesia genus in dogs from endemic areas of Lyme disease in north-western Poland]. Wiad Parazytol. 2004;50(3):555-61.

54. Santos AS, Alexandre N, Sousa R, Nuncio MS, Bacellar F, Dumler JS. Serological and molecular survey of Anaplasma species infection in dogs with suspected tickborne disease in Portugal. Vet Rec. 2009;164(6):168-71.

55. Egenvall A, Bonnett BN, Gunnarsson A, Hedhammar A, Shoukri M, Bornstein S, et al. Sero-prevalence of granulocytic Ehrlichia spp. and Borrelia burgdorferi sensu lato in Swedish dogs 1991-94. Scand J Infect Dis. 2000;32(1):19-25.

56. Jaderlund KH, Egenvall A, Bergstrom K, Hedhammar A. Seroprevalence of Borrelia burgdorferi sensu lato and Anaplasma phagocytophilum in dogs with neurological signs. Vet Rec. 2007;160(24):825-31.

57. Shaw SE, Binns SH, Birtles RJ, Day MJ, Smithson R, Kenny MJ. Molecular evidence of tick-transmitted infections in dogs and cats in the United Kingdom. Vet Rec. 2005;157(21):645-8.

58. Aguirre E, Tesouro MA, Ruiz L, Amusategui I, Sainz A. Genetic characterization of Anaplasma (Ehrlichia) platys in dogs in Spain. J Vet Med B Infect Dis Vet Public Health. 2006;53(4):197-200.

59. Cardoso L, Tuna J, Vieira L, Yisaschar-Mekuzas Y, Baneth G. Molecular detection of Anaplasma platys and Ehrlichia canis in dogs from the North of Portugal. Vet J. 2010;183(2):232-3.

60. Beaufils JP, Inokuma H, Martin-Granel J, Jumelle P, Barbault-Jumelle M, Brouqui P. Anaplasma platys (Ehrlichia platys) infection in a dog in France: description of the case, and characterization of the agent. Rev Med Vet. 2002;153:85-90.

61. Ulutas B, Bayramli G, Karangec T. First case of Anaplasma (Ehrlichia) platys infection in a dog in Turkey. Turk J Vet Anim Sci. 2007;31:279-82.

62. Kontos VI, Papadopoulos O, French TW. Natural and experimental canine infections with a Greek strain of Ehrlichia platys. Vet Clin Pathol. 1991;20(4):101-5.

63. Dyachenko V, Pantchev N, Balzer HJ, Meyersen A, Straubinger RK. First case of Anaplasma platys infection in a dog from Croatia. Parasit Vectors. 2012;5:49.

64. Andersson M, Turcitu MA, Stefanache M, Tamba P, Barbuceanu F, Chitimia L. First evidence of Anaplasma platys and Hepatozoon canis co-infection in a dog from Romania-a case report. Ticks Tick Borne Dis. 2013;4(4):317-9. 
65. Ramos RA, Latrofa MS, Giannelli A, Lacasella V, Campbell BE, Dantas-Torres F, et al. Detection of Anaplasma platys in dogs and Rhipicephalus sanguineus group ticks by a quantitative real-time PCR. Vet Parasitol. 2014;205(1-2):285-8.

66. de Caprariis D, Dantas-Torres F, Capelli G, Mencke N, Stanneck D, Breitschwerdt EB, et al. Evolution of clinical, haematological and biochemical findings in young dogs naturally infected by vector-borne pathogens. Vet Microbiol. 2011;149(1-2):206-12.

67. Otranto D, de Caprariis D, Lia RP, Tarallo V, Lorusso V, Testini G, et al. Prevention of endemic canine vector-borne diseases using imidacloprid $10 \%$ and permethrin $50 \%$ in young dogs: a longitudinal field study. Vet Parasitol. 2010;172(3-4):323-32.

68. Sparagano OA, de Vos AP, Paoletti B, Camma C, de Santis P, Otranto D, et al. Molecular detection of Anaplasma platys in dogs using polymerase chain reaction and reverse line blot hybridization. J Vet Diagn Invest. 2003;15(6):527-34.

69. Groves MG, Dennis GL, Amyx HL, Huxsoll DL. Transmission of Ehrlichia canis to dogs by ticks (Rhipicephalus sanguineus). Am J Vet Res. 1975;36(7):937-40.

70. Smith RD, Sells DM, Stephenson EH, Ristic MR, Huxsoll DL. Development of Ehrlichia canis, causative agent of canine ehrlichiosis, in the tick Rhipicephalus sanguineus and its differentiation from a symbiotic Rickettsia. Am J Vet Res. 1976;37(2):119-26.

71. Fourie JJ, Stanneck D, Luus HG, Beugnet F, Wijnveld M, Jongejan F. Transmission of Ehrlichia canis by Rhipicephalus sanguineus ticks feeding on dogs and on artificial membranes. Vet Parasitol. 2013;197(3-4):595-603.

72. Gray J, Dantas-Torres F, Estrada-Pena A, Levin M. Systematics and ecology of the brown dog tick, Rhipicephalus sanguineus. Ticks Tick Borne Dis. 2013;4(3):171-80.

73. Gray JS, Dautel H, Estrada-Pena A, Kahl O, Lindgren E. Effects of climate change on ticks and tick-borne diseases in europe. Interdiscip Perspect Infect Dis. 2009;2009:593232.

74. Uspensky I, loffe-Uspensky I. The dog factor in brown dog tick Rhipicephalus sanguineus (Acari: Ixodidae) infestations in and near human dwellings. Int J Med Microbiol. 2002;291 Suppl 33:156-63.

75. Jaenson TG, Jaenson DG, Eisen L, Petersson E, Lindgren E. Changes in the geographical distribution and abundance of the tick Ixodes ricinus during the past 30 years in Sweden. Parasit Vectors. 2012;5:8

76. Medlock JM, Hansford KM, Bormane A, Derdakova M, Estrada-Pena A, George JC, et al. Driving forces for changes in geographical distribution of Ixodes ricinus ticks in Europe. Parasit Vectors. 2013;6:1.

77. Estrada-Pena A, Farkas R, Jaenson TG, Koenen F, Madder M, Pascucci I, et al. Association of environmental traits with the geographic ranges of ticks (Acari: Ixodidae) of medical and veterinary importance in the western Palearctic. A digital data set. Exp Appl Acarol. 2013;59(3):351-66.

78. Yasyukevich W, Kazakova EV, Popov IO, Semenov SM. Distribution of Ixodes ricinus L., 1758 and Ixodes persulcatus Shulze, 1930 (Parasitoformes, Ixodidae) in Russia and adjacent countries in view of observable climate changes. Dokl Earth Sci. 2009;427(2):1030-4.

79. Ecker M, Allison SL, Meixner T, Heinz FX. Sequence analysis and genetic classification of tick-borne encephalitis viruses from Europe and Asia. J Gen Virol. 1999;80(Pt 1):179-85.

80. Alekseev AN, Dubinina HV, Van De Pol I, Schouls LM. Identification of Ehrlichia spp. and Borrelia burgdorferi in Ixodes ticks in the Baltic regions of Russia. J Clin Microbiol. 2001;39(6):2237-42.

81. Hamel D, Silaghi C, Zapadynska S, Kudrin A, Pfister K. Vector-borne pathogens in ticks and EDTA-blood samples collected from client-owned dogs, Kiev. Ukraine Ticks Tick Borne Dis. 2013;4(1-2):152-5.

82. Movila A, Toderas I, Uspenskaia I, Conovalov J. Molecular detection of tick-borne pathogens in Ixodes ricinus from Moldova collected in 1960. Ticks Tick Borne Dis. 2013;4(4):359-61.

83. Simpson RM, Gaunt SD, Hair JA, Kocan KM, Henk WG, Casey HW. Evaluation of Rhipicephalus sanguineus as a potential biologic vector of Ehrlichia platys. Am J Vet Res. 1991;52(9):1537-41.

84. Sanogo YO, Davoust B, Inokuma H, Camicas $J$, Parola P, Brouqui P. First evidence of Anaplasma platys in Rhipicephalus sanguineus (Acari: Ixodida) collected from dogs in Africa. Onderstepoort J Vet Res. 2003;70(3):205-12.

85. Johnson EM, Ewing SA, Barker RW, Fox JC, Crow DW, Kocan KM. Experimental transmission of Ehrlichia canis (Rickettsiales: Ehrlichieae) by Dermacentor variabilis (Acari: Ixodidae). Vet Parasitol. 1998;74(2-4):277-88.
86. McQuiston JH, Childs JE, Chamberland ME, Tabor E. Transmission of tick-borne agents of disease by blood transfusion: a review of known and potential risks in the United States. Transfusion. 2000;40(3):274-84

87. Egenvall A, Bjoersdorff A, Lilliehook I, Olsson Engvall E, Karlstam E, Artursson $K$, et al. Early manifestations of granulocytic ehrlichiosis in dogs inoculated experimentally with a Swedish Ehrlichia species isolate. Vet Rec. 1998;143(15):412-7.

88. Wardrop KJ, Reine N, Birkenheuer A, Hale A, Hohenhaus A, Crawford C, et al. Canine and feline blood donor screening for infectious disease. J Vet Intern Med. 2005;19(1):135-42.

89. Kohn B. Anaplasma phagocytophilum in the dog - update on epidemiology and clinical disease. In: Canine vector-borne disease world forum. New York: Bayer HealthCare Animal Health; 2010. p. 36-43. 12-15 April.

90. Gaunt S, Beall M, Stillman B, Lorentzen L, Diniz P, Chandrashekar R, et al. Experimental infection and co-infection of dogs with Anaplasma platys and Ehrlichia canis: hematologic, serologic and molecular findings. Parasit Vectors. 2010;3(1):33.

91. Ebani W, Verin R, Fratini F, Poli A, Cerri D. Molecular survey of Anaplasma phagocytophilum and Ehrlichia canis in red foxes (Vulpes vulpes) from central Italy. J Wildl Dis. 2011;47(3):699-703.

92. Fishman Z, Gonen L, Harrus S, Strauss-Ayali D, King R, Baneth G. A serosurvey of Hepatozoon canis and Ehrlichia canis antibodies in wild red foxes (Vulpes vulpes) from Israel. Vet Parasitol. 2004;119(1):21-6.

93. Torina A, Blanda V, Antoci F, Scimeca S, D'Agostino R, Scariano E, et al. A Molecular survey of Anaplasma spp., Rickettsia spp., Ehrlichia canis and Babesia microti in foxes and fleas from Sicily. Transbound Emerg Dis. 2013;60 Suppl 2:125-30.

94. Breitschwerdt EB, Abrams-Ogg AC, Lappin MR, Bienzle D, Hancock SI, Cowan SM, et al. Molecular evidence supporting Ehrlichia canis-like infection in cats. J Vet Intern Med. 2002;16(6):642-9.

95. Andre MR, Adania CH, Machado RZ, Allegretti SM, Felippe PA, Silva KF, et al. Molecular and serologic detection of Ehrlichia spp. in endangered Brazilian wild captive felids. J Wildl Dis. 2010;46(3):1017-23.

96. Braga Mdo S, Andre MR, Freschi CR, Teixeira MC, Machado RZ. Molecular and serological detection of Ehrlichia spp. in cats on Sao Luis Island, Maranhao, Brazil. Rev Bras Parasitol Vet. 2012;21(1):37-41.

97. Maia C, Ramos C, Coimbra M, Bastos F, Martins A, Pinto P, et al. Bacterial and protozoal agents of feline vector-borne diseases in domestic and stray cats from southern Portugal. Parasit Vectors. 2014;7:115.

98. Groen J, Koraka P, Nur YA, Avsic-Zupanc T, Goessens WH, Ott A, et al. Serologic evidence of ehrlichiosis among humans and wild animals in The Netherlands. Eur J Clin Microbiol Infect Dis. 2002;21(1):46-9.

99. Ismail N, Bloch KC, McBride JW. Human ehrlichiosis and anaplasmosis. Clin Lab Med. 2010;30(1):261-92.

100. Nicholson WL, Allen KE, McQuiston JH, Breitschwerdt EB, Little SE. The increasing recognition of rickettsial pathogens in dogs and people. Trends Parasitol. 2010;26(4):205-12.

101. Lima ML, Soares PT, Ramos CA, Araujo FR, Ramos RA, Souza II, et al. Molecular detection of Anaplasma platys in a naturally-infected cat in Brazil. Braz J Microbiol. 2010;41(2):381-5.

102. Qurollo BA, Balakrishnan N, Cannon CZ, Maggi RG, Breitschwerdt EB. Co-infection with Anaplasma platys, Bartonella henselae, Bartonella koehlerae and 'Candidatus Mycoplasma haemominutum' in a cat diagnosed with splenic plasmacytosis and multiple myeloma. J Feline Med Surg. 2014;16(8):713-20.

103. Perez $M$, Rikihisa $Y$, Wen $B$. Ehrlichia canis-like agent isolated from a man in Venezuela: antigenic and genetic characterization. J Clin Microbiol. 1996;34(9):2133-9.

104. Fishbein DB, Dawson JE, Robinson LE. Human ehrlichiosis in the United States, 1985 to 1990. Ann Intern Med. 1994;120(9):736-43.

105. Ganguly S, Mukhopadhayay SK. Tick-borne ehrlichiosis infection in human beings. J Vector Borne Dis. 2008;45(4):273-80.

106. Bakken JS, Dumler JS, Chen SM, Eckman MR, Van Etta LL, Walker DH. Human granulocytic ehrlichiosis in the upper Midwest United States. A new species emerging? JAMA. 1994;272(3):212-8.

107. Parola P, Davoust B, Raoult D. Tick- and flea-borne rickettsial emerging zoonoses. Vet Res. 2005;36(3):469-92.

108. Dumler JS, Choi KS, Garcia-Garcia JC, Barat NS, Scorpio DG, Garyu JW, et al. Human granulocytic anaplasmosis and Anaplasma phagocytophilum. Emerg Infect Dis. 2005;11(12):1828-34. 
109. Maggi RG, Mascarelli PE, Havenga LN, Naidoo V, Breitschwerdt EB. Co-infection with Anaplasma platys, Bartonella henselae and Candidatus Mycoplasma haematoparvum in a veterinarian. Parasit Vectors. 2013;6:103.

110. Arraga-Alvarado CM, Qurollo B, Parra OC, Berrueta MA, Hegarty BC, Breitschwerdt EB. Molecular Evidence of Anaplasma platys Infection in Two Women from Venezuela. Am J Trop Med Hyg. 2014;91(6):1161-5.

111. Buller RS, Arens M, Hmiel SP, Paddock CD, Sumner JW, Rikhisa Y, et al. Ehrlichia ewingii, a newly recognized agent of human ehrlichiosis. N Engl J Med. 1999;341(3):148-55

112. Allsopp MT, Louw M, Meyer EC. Ehrlichia ruminantium: an emerging human pathogen? Ann N Y Acad Sci. 2005;1063:358-60.

113. Allsopp MT, Allsopp BA. Novel Ehrlichia genotype detected in dogs in South Africa. J Clin Microbiol. 2001;39(11):4204-7.

114. Gutierrez CN, Martinez M, Sanchez E, De Vera M, Rojas M, Ruiz J, et al. Cultivation and molecular identification of Ehrlichia canis and Ehrlichia chaffeensis from a naturally co-infected dog in Venezuela. Vet Clin Pathol. 2008:37(3):258-65.

115. Beall MJ, Alleman AR, Breitschwerdt EB, Cohn LA, Couto CG, Dryden MW, et al. Seroprevalence of Ehrlichia canis, Ehrlichia chaffeensis and Ehrlichia ewingii in dogs in North America. Parasit Vectors. 2012;5:29.

116. Ndip LM, Ndip RN, Esemu SN, Walker DH, McBride JW. Predominance of Ehrlichia chaffeensis in Rhipicephalus sanguineus ticks from kennel-confined dogs in Limbe. Cameroon Exp Appl Acarol. 2010;50(2):163-8.

117. Pritt BS, Sloan LM, Johnson DK, Munderloh UG, Paskewitz SM, McElroy KM, et al. Emergence of a new pathogenic Ehrlichia species, Wisconsin and Minnesota, 2009. N Engl J Med. 2011;365(5):422-9.

118. Hegarty BC, Maggi RG, Koskinen P, Beall MJ, Eberts M, Chandrashekar R, et al. Ehrlichia muris infection in a dog from Minnesota. J Vet Intern Med. 2012;26(5):1217-20.

119. Nyindo M, Huxsoll DL, Ristic M, Kakoma I, Brown JL, Carson CA, et al. Cell-mediated and humoral immune responses of German Shepherd Dogs and Beagles to experimental infection with Ehrlichia canis. Am J Vet Res. 1980;41(2):250-4.

120. Harrus S, Kass PH, Klement E, Waner T. Canine monocytic ehrlichiosis: a retrospective study of 100 cases, and an epidemiological investigation of prognostic indicators for the disease. Vet Rec. 1997;141(14):360-3.

121. Costa Jr LM, Rembeck K, Ribeiro MF, Beelitz P, Pfister K, Passos LM Sero-prevalence and risk indicators for canine ehrlichiosis in three rural areas of Brazil. Vet J. 2007;174(3):673-6.

122. Rodriguez-Vivas Rl, Albornoz RE, Bolio GM. Ehrlichia canis in dogs in Yucatan, Mexico: seroprevalence, prevalence of infection and associated factors. Vet Parasitol. 2005;127(1):75-9.

123. Watanabe M, Okuda M, Tsuji M, Inokuma H. Seroepidemiological study of canine ehrlichial infections in Yamaguchi prefecture and surrounding areas of Japan. Vet Parasitol. 2004:124(1-2):101-7.

124. Egenvall $A E$, Hedhammar AA, Bjoersdorff Al. Clinical features and serology of 14 dogs affected by granulocytic ehrlichiosis in Sweden. Vet Rec. 1997;140(9):222-6.

125. McClure JC, Crothers ML, Schaefer JJ, Stanley PD, Needham GR, Ewing SA, et al. Efficacy of a doxycycline treatment regimen initiated during three different phases of experimental ehrlichiosis. Antimicrob Agents Chemother. 2010;54(12):5012-20

126. Harrus S, Waner T, Aizenberg I, Foley JE, Poland AM, Bark H. Amplification of ehrlichial DNA from dogs 34 months after infection with Ehrlichia canis. J Clin Microbiol. 1998;36(1):73-6.

127. Waner T, Harrus S, Bark H, Bogin E, Avidar Y, Keysary A. Characterization of the subclinical phase of canine ehrlichiosis in experimentally infected beagle dogs. Vet Parasitol. 1997;69(3-4):307-17.

128. Mylonakis ME, Koutinas AF, Breitschwerdt EB, Hegarty BC, Billinis CD, Leontides LS, et al. Chronic canine ehrlichiosis (Ehrlichia canis): a retrospective study of 19 natural cases. J Am Anim Hosp Assoc. 2004;40(3):174-84

129. Egenvall A, Lilliehook I, Bjoersdorff A, Engvall EO, Karlstam E, Artursson K, et al. Detection of granulocytic Ehrlichia species DNA by PCR in persistently infected dogs. Vet Rec. 2000;146(7):186-90.

130. Gaunt SD, Baker DC, Babin SS. Platelet aggregation studies in dogs with acute Ehrlichia platys infection. Am J Vet Res. 1990;51(2):290-3.

131. Harvey JW. Thrombocytotrophic anaplasmosis (A.platys [E.platys] infection) In: Greene CG, editor. Infectious diseases of the dog and cat. 3rd ed. St. Louis: Saunders Elsevier; 2006. p. 229-31.

132. Greig B, Asanovich KM, Armstrong PJ, Dumler JS. Geographic, clinical, serologic, and molecular evidence of granulocytic ehrlichiosis, a likely zoonotic disease, in Minnesota and Wisconsin dogs. J Clin Microbiol. 1996;34(1):44-8.
133. Varela F, Font X, Valladares JE, Alberola J. Thrombocytopathia and light-chain proteinuria in a dog naturally infected with Ehrlichia canis. J Vet Intern Med. 1997;11(5):309-11.

134. Breitschwerdt EB, Hegarty BC, Hancock SI. Sequential evaluation of dogs naturally infected with Ehrlichia canis, Ehrlichia chaffeensis, Ehrlichia equi, Ehrlichia ewingii, or Bartonella vinsonii. J Clin Microbiol. 1998;36(9):2645-51.

135. Goldman EE, Breitschwerdt EB, Grindem CB, Hegarty BC, Walls JJ, Dumler JS. Granulocytic ehrlichiosis in dogs from North Carolina and Virginia. J Vet Intern Med. 1998;12(2):61-70.

136. Lilliehöök I, Egenvall A, Twedten HW. Hematopathology in dogs experimentally infected with a Swedish granulocytic Ehrlichia species. Vet Clin Pathol. 1998;27(4):116-22.

137. Neer TM. Canine monocytic and granulocytic ehrlichiosis. In: Greene CE, editor. Infectious Diseases of the Dog and Cat. 2nd ed. Philadelphia: W.B. Saunders Co; 1998. p. 139-47.

138. Breitschwerdt EB. Obligate intracellular pathogens. In: Ettinger SJ, Feldman EC, editors. Textbook of Veterinary Internal Medicine. 6th ed. Philadelphia, PA: W.B. Saunders Co; 2005. p. 631-2.

139. Komnenou AA, Mylonakis ME, Kouti V, Tendoma L, Leontides L, Skountzou E, et al. Ocular manifestations of natural canine monocytic ehrlichiosis (Ehrlichia canis): a retrospective study of 90 cases. Vet Ophthalmol. 2007;10(3):137-42

140. Leiva M, Naranjo C, Pena MT. Ocular signs of canine monocytic ehrlichiosis: a retrospective study in dogs from Barcelona. Spain Vet Ophthalmol. 2005;8(6):387-93.

141. Diniz PP, de Morais HS, Breitschwerdt EB, Schwartz DS. Serum cardiac troponin I concentration in dogs with ehrlichiosis. J Vet Intern Med. 2008;22(5):1136-43.

142. Little SE. Ehrlichiosis and anaplasmosis in dogs and cats. Vet Clin North Am Small Anim Pract. 2010;40(6):1121-40.

143. Bellah JR, Shull RM, Selcer EV. Ehrlichia canis-related polyarthritis in a dog. J Am Vet Med Assoc. 1986;189(8):922-3.

144. Cowell RL, Tyler RD, Clinkenbeard KD, Meinkoth JH. Ehrlichiosis and polyarthritis in three dogs. J Am Vet Med Assoc. 1988;192(8):1093-5.

145. Greig B, Armstrong PJ. Canine granulocytotrophic anaplasmosis (A. phagocytophilum infection). In: Greene CG, editor. Infectious diseases of the dog and cat. 3rd ed. St. Louis: Saunders Elsevier; 2006. p. 219-24.

146. Alleman R, Heather W: An update on anaplasmosis in dogs. Vet Med 2008, April:212-220

147. Kohn B, Galke D, Beelitz P, Pfister K. Clinical features of canine granulocytic anaplasmosis in 18 naturally infected dogs. J Vet Intern Med. 2008;22(6):1289-95.

148. Granick JL, Armstrong PJ, Bender JB. Anaplasma phagocytophilum infection in dogs: 34 cases (2000-2007). J Am Vet Med Assoc. 2009;234(12):1559-65.

149. Ravnik U, Tozon N, Strasek K, Avsic Zupanc T. Clinical and haematological features in Anaplasma phagocytophilum seropositive dogs. Clin Microbiol Infect. 2009;15 Suppl 2:39-40.

150. Mazepa AW, Kidd LB, Young KM, Trepanier LA. Clinical presentation of 26 anaplasma phagocytophilum-seropositive dogs residing in an endemic area. J Am Anim Hosp Assoc. 2010;46(6):405-12

151. Eberts MD. Vissotto de Paiva Diniz PP, Beall MJ, Stillman BA, Chandrashekar R, Breitschwerdt EB: Typical and atypical manifestations of Anaplasma phagocytophilum infection in dogs. J Am Anim Hosp Assoc. 2011:47(6):e86-94

152. Maretzki CH, Fisher DJ, Greene CE. Granulocytic ehrlichiosis and meningitis in a dog. J Am Vet Med Assoc. 1994;205(11):1554-6.

153. Jaderlund KH, Bergstrom K, Egenvall A, Hedhammar A. Cerebrospinal fluid PCR and antibody concentrations against Anaplasma phagocytophilum and Borrelia burgdorferi sensu lato in dogs with neurological signs. J Vet Intern Med. 2009;23(3):669-72.

154. Barber RM, Li Q, Diniz PP, Porter BF, Breitschwerdt EB, Claiborne MK, et al. Evaluation of brain tissue or cerebrospinal fluid with broadly reactive polymerase chain reaction for Ehrlichia, Anaplasma, spotted fever group Rickettsia, Bartonella, and Borrelia species in canine neurological diseases (109 cases). J Vet Intern Med. 2010;24(2):372-8.

155. Lazzerini K, Tipold A, Kornberg M, Silaghi C, Mietze A, Lübke-Becker A, et al. Meningitis and meningoencephalitis of unknown etiology in dogs - are canine vector borne diseases (CVBD) triggering the diseases? In: Proceedings of 26th Symposium ESVN-ECVN2013; Paris. J Vet Intern Med. 2014;28(3):968--969.

156. Glaze MB, Gaunt SD. Uveitis associated with Ehrlichia platys infection in a dog. J Am Vet Med Assoc. 1986;189(8):916-7. 
157. Harrus S, Aroch I, Lavy E, Bark H. Clinical manifestations of infectious canine cyclic thrombocytopenia. Vet Rec. 1997;141(10):247-50.

158. Sainz A, Amusategui I, Tesouro MA. Ehrlichia platys infection and disease in dogs in Spain. J Vet Diagn Invest. 1999;11(4):382-4.

159. Cohn LA. Ehrlichiosis and related infections. Vet Clin North Am Small Anim Pract. 2003;33(4):863-84.

160. Mylonakis ME, Koutinas AF, Billinis C, Leontides LS, Kontos V, Papadopoulos $\mathrm{O}$, et al. Evaluation of cytology in the diagnosis of acute canine monocytic ehrlichiosis (Ehrlichia canis): a comparison between five methods. Vet Microbiol. 2003;91(2-3):197-204.

161. Mylonakis ME, Borjesson DL, Leontides L, Siarkou VI, Theodorou K, Koutinas AF. Cytologic patterns of lymphadenopathy in canine monocytic ehrlichiosis. Vet Clin Pathol. 2011;40(1):78-83.

162. Otranto D, Testini G, Dantas-Torres F, Latrofa MS, Diniz PP, de Caprariis D, et al. Diagnosis of canine vector-borne diseases in young dogs: a longitudinal study. J Clin Microbiol. 2010;48(9):3316-24.

163. De Tommasi AS, Baneth G, Breitschwerdt EB, Stanneck D, Dantas-Torres F, Otranto D, et al. Anaplasma platys in Bone Marrow Megakaryocytes of Young Dogs. J Clin Microbiol. 2014;52(6):2231-4.

164. Harrus S, Alleman AR, Bark H, Mahan SM, Waner T. Comparison of three enzyme-linked immunosorbant assays with the indirect immunofluorescent antibody test for the diagnosis of canine infection with Ehrlichia canis. Vet Microbiol. 2002;86(4):361-8.

165. Waner T, Harrus S, Jongejan F, Bark H, Keysary A, Cornelissen AW. Significance of serological testing for ehrlichial diseases in dogs with special emphasis on the diagnosis of canine monocytic ehrlichiosis caused by Ehrlichia canis. Vet Parasitol. 2001;95(1):1-15.

166. Wen B, Rikihisa Y, Mott JM, Greene R, Kim HY, Zhi N, et al. Comparison of nested PCR with immunofluorescent-antibody assay for detection of Ehrlichia canis infection in dogs treated with doxycycline. J Clin Microbiol. 1997;35(7):1852-5.

167. Maggi RG, Birkenheuer AJ, Hegarty BC, Bradley JM, Levy MG, Breitschwerdt EB. Comparison of serological and molecular panels for diagnosis of vector-borne diseases in dogs. Parasit Vectors. 2014;7:127.

168. Harrus S, Waner T, Aizenberg I, Bark H. Therapeutic effect of doxycycline in experimental subclinical canine monocytic ehrlichiosis: evaluation of a 6-week course. J Clin Microbiol. 1998;36(7):2140-2.

169. Baneth G, Harrus S, Ohnona FS, Schlesinger Y. Longitudinal quantification of Ehrlichia canis in experimental infection with comparison to natural infection. Vet Microbiol. 2009;136(3-4):321-5.

170. Breitschwerdt EB, Hegarty BC, Hancock SI. Doxycycline hyclate treatment of experimental canine ehrlichiosis followed by challenge inoculation with two Ehrlichia canis strains. Antimicrob Agents Chemother. 1998:42(2):362-8.

171. Sainz A, Tesouro MA, Amusategui I, Rodriguez F, Mazzucchelli F, Rodriguez M. Prospective comparative study of 3 treatment protocols using doxycycline or imidocarb dipropionate in dogs with naturally occurring ehrlichiosis. J Vet Intern Med. 2000;14(2):134-9

172. French TW, Harvey JW. Serologic diagnosis of infectious cyclic thrombocytopenia in dogs using an indirect fluorescent antibody test. Am J Vet Res. 1983:44(12):2407-11

173. Chandrashekar R, Mainville CA, Beall MJ, O'Connor T, Eberts MD, Alleman $A R$, et al. Performance of a commercially available in-clinic ELISA for the detection of antibodies against Anaplasma phagocytophilum, Ehrlichia canis, and Borrelia burgdorferi and Dirofilaria immitis antigen in dogs. Am J Vet Res. 2010;71(12):1443-50.

174. Alleman AR, Wamsley HL, Abbott J, et al. Experimental Anaplasma phagocytophilum infection of dogs by intravenous inoculation of human and canine isolates and treatment with doxycycline. Vet Pathol. 2007:44:19.

175. Alleman A, Chandrashekar R, Beall M, Cyr K, Barbet A, Lundgren A, et al. Experimental inoculation of dogs with a human isolate (NY18) of Anaplasma phagocytophilum and demonstration of persistent infection following doxycycline therapy. J Vet Intern Med. 2006;20:763.

176. Harrus S, Kenny M, Miara L, Aizenberg I, Waner T, Shaw S. Comparison of simultaneous splenic sample PCR with blood sample PCR for diagnosis and treatment of experimental Ehrlichia canis infection. Antimicrob Agents Chemother. 2004;48(11):4488-90.

177. Sainz A. Ehrlichiosis/Anaplasmosis. In: Miró G, Solano-Gallego L, editors. Enfermedades Vectoriales del perro y del gato. 1st ed. Madrid: Ed. Achalantis; 2011. p. 203-26.
178. Gal A, Harrus S, Arcoh I, Lavy E, Aizenberg I, Mekuzas-Yisaschar Y, et al. Coinfection with multiple tick-borne and intestinal parasites in a 6-week-old dog. Can Vet J. 2007;48(6):619-22.

179. Beall MJ, Chandrashekar R, Eberts MD, Cyr KE, Diniz PP, Mainville C, et al. Serological and molecular prevalence of Borrelia burgdorferi, Anaplasma phagocytophilum, and Ehrlichia species in dogs from Minnesota. Vector Borne Zoonotic Dis. 2008;8(4):455-64.

180. Grab DJ, Nyarko E, Barat NC, Nikolskaia OV, Dumler JS. Anaplasma phagocytophilum-Borrelia burgdorferi coinfection enhances chemokine, cytokine, and matrix metalloprotease expression by human brain microvascular endothelial cells. Clin Vaccine Immunol. 2007;14(11):1420-4.

181. Foley JE, Brown RN, Gabriel MW, Henn J, Drazenovich N, Kasten R, et al. Spatial analysis of the exposure of dogs in rural north-coastal California to vectorborne pathogens. Vet Rec. 2007;161(19):653-7.

182. Cortese L, Pelagalli A, Piantedosi D, Cestaro A, Di Loria A, Lombardi P, et al. Effects of therapy on haemostasis in dogs infected with Leishmania infantum, Ehrlichia canis, or both combined. Vet Rec. 2009;164(14):433-4.

183. Mekuzas Y, Gradoni L, Oliva G, Foglia Manzillo V, Baneth G. Ehrlichia canis and Leishmania infantum co-infection: a 3-year longitudinal study in naturally exposed dogs. Clin Microbiol Infect. 2009;15 Suppl 2:30-1.

184. Matthewman LA, Kelly PJ, Brouqui P, Raoult D. Further evidence for the efficacy of imidocarb dipropionate in the treatment of Ehrlichia canis infection. J S Afr Vet Assoc. 1994;65(3):104-7.

185. Price JE, Dolan TT. A comparison of the efficacy of imidocarb dipropionate and tetracycline hydrochloride in the treatment of canine ehrlichiosis. Vet Rec. 1980;107(12):275-7.

186. Eddlestone SM, Neer TM, Gaunt SD, Corstvet R, Gill A, Hosgood G, et al. Failure of imidocarb dipropionate to clear experimentally induced Ehrlichia canis infection in dogs. J Vet Intern Med. 2006;20(4):840-4.

187. Kelly PJ, Matthewman LA, Brouqui P, Raoult D. Lack of susceptibility of Ehrlichia canis to imidocarb dipropionate in vitro. J S Afr Vet Assoc. 1998;69(2):55-6.

188. Schaefer JJ, Kahn J, Needham GR, Rikihisa Y, Ewing SA, Stich RW. Antibiotic clearance of Ehrlichia canis from dogs infected by intravenous inoculation of carrier blood. Ann N Y Acad Sci. 2008;1149:263-9.

189. Theodorou K, Mylonakis ME, Siarkou VI, Leontides L, Koutinas AF, Koutinas CK, et al. Efficacy of rifampicin in the treatment of experimental acute canine monocytic ehrlichiosis. J Antimicrob Chemother. 2013;68(7):1619-26.

190. Maurin M, Bakken JS, Dumler JS. Antibiotic susceptibilities of Anaplasma (Ehrlichia) phagocytophilum strains from various geographic areas in the United States. Antimicrob Agents Chemother. 2003:47(1):413-5.

191. Diniz PPVP, Breitschwerdt E. Canine granulocytotropic anaplasmosis (A. phagocytophilum infection). In: Greene CE, editor. Infectious diseases of the dog and cat. 4th ed. Philadelphia: Saunders; 2011. p. 244-54.

192. Chang WL, Su WL, Pan MJ. Two-step PCR in the evaluation of antibiotic treatment for Ehrlichia platys infection. J Vet Med Sci. 1997;59(9):849-51.

193. Aroch I, Harrus S. The use of recombinant human colony stimulating factor and recombinant human erythropoietin in the treatment of severe pancytopenia due to canine monocytic ehrlichiosis. Israel J Vet Med. 2001;56(2):65-9.

194. Perille AL, Matus RE. Canine ehrlichiosis in six dogs with persistently increased antibody titers. J Vet Intern Med. 1991;5(3):195-8.

195. Massa KL, Gilger BC, Miller TL, Davidson MG. Causes of uveitis in dogs: 102 cases (1989-2000). Vet Ophthalmol. 2002;5(2):93-8.

196. Heeb HL, Wilkerson MJ, Chun R, Ganta RR. Large granular lymphocytosis, lymphocyte subset inversion, thrombocytopenia, dysproteinemia, and positive Ehrlichia serology in a dog. J Am Anim Hosp Assoc. 2003;39(4):379-84.

197. van Heerden J. A retrospective study on 120 natural cases of canine ehrlichiosis. J S Afr Vet Assoc. 1982;53(1):17-22.

198. Shipov A, Klement E, Reuveni-Tager L, Waner T, Harrus S. Prognostic indicators for canine monocytic ehrlichiosis. Vet Parasitol. 2008;153(1-2):131-8.

199. Mylonakis ME, Ceron JJ, Leontides L, Siarkou VI, Martinez S, Tvarijonaviciute $A$, et al. Serum acute phase proteins as clinical phase indicators and outcome predictors in naturally occurring canine monocytic ehrlichiosis. J Vet Intern Med. 2011;25(4):811-7.

200. Carrade DD, Foley JE, Borjesson DL, Sykes JE. Canine granulocytic anaplasmosis: a review. J Vet Intern Med. 2009;23(6):1129-41.

201. Martin AR, Brown GK, Dunstan RH, Roberts TK. Anaplasma platys: an improved PCR for its detection in dogs. Exp Parasitol. 2005;109(3):176-80.

202. Horowitz HW, Aguero-Rosenfeld M, Dumler JS, McKenna DF, Hsieh TC, Wu J, et al. Reinfection with the agent of human granulocytic ehrlichiosis. Ann Intern Med. 1998;129(6):461-3. 
203. Dantas-Torres F. The brown dog tick, Rhipicephalus sanguineus

(Latreille, 1806) (Acari: Ixodidae): from taxonomy to control. Vet Parasitol. 2008;152(3-4):173-85.

204. Therapy Tables [www.esccap.org]

205. Pereira CP, Oliveira PR, Furquim KC, Bechara GH, Camargo-Mathias MI. Effects of fipronil (active ingredient of Frontline) on salivary gland cells of Rhipicephalus sanguineus females (Latreille, 1806) (Acari: Ixodidae). Vet Parasitol. 2009:166(1-2):124-30

206. Rudoler N, Baneth G, Eyal O, van Straten M, Harrus S. Evaluation of an attenuated strain of Ehrlichia canis as a vaccine for canine monocytic ehrlichiosis. Vaccine. 2012;31(1):226-33.

\section{Submit your next manuscript to BioMed Central} and take full advantage of:

- Convenient online submission

- Thorough peer review

- No space constraints or color figure charges

- Immediate publication on acceptance

- Inclusion in PubMed, CAS, Scopus and Google Scholar

- Research which is freely available for redistribution 